\title{
Instability of Financial Markets and Preference Heterogeneity
}

\author{
Günter Franke $^{1}$ and Erik Lüders ${ }^{2}$ \\ ${ }^{1}$ Department of Economics, University of Konstanz, 78457 Konstanz, Germany \\ ${ }^{2}$ McKinsey E Company, Inc., Taunustor 2, 60311 Frankfurt/Main, Germany \\ Correspondence should be addressed to Günter Franke, guenter.franke@uni-konstanz.de
}

Received 22 December 2009; Accepted 7 March 2010

Academic Editor: Wing-Keung Wong

Copyright (C) 2010 G. Franke and E. Lüders. This is an open access article distributed under the Creative Commons Attribution License, which permits unrestricted use, distribution, and reproduction in any medium, provided the original work is properly cited.

This paper presents a simple rational expectations model of intertemporal asset pricing relating instability of stock return characteristics to heterogeneity in investor preferences. Heterogeneity is likely to generate declining aggregate relative risk aversion. This leads to variability in expected asset returns, volatility, and autocorrelation. The stronger this variability is, the more heterogeneous preferences are, implying more instability of financial markets. Stock market crashes may be observed if relative risk aversion differs strongly across investors.

\section{Introduction}

The last twenty five years witnessed various sudden shifts in valuation so that instability of financial markets does not seem to be the exception but the rule. The stock market crashes of 1987, 1998, and 2001 and most recently the subprime crisis are the most prominent examples. In addition to these events, financial markets show more signs of instability. Financial instability is measured by the variability in characteristics of stock return processes, in particular, expected return, volatility, and autocorrelation. The more these characteristics vary, the stronger is instability.

This paper shows that financial market instability is a natural consequence of heterogeneous investor preferences. In a simple intertemporal equilibrium model we show that heterogeneous investor preferences are likely to cause declining aggregate relative risk aversion. Financial instability is driven by the instability in the decline of aggregate relative risk aversion. Our model delivers rather stable time series characteristics of stock returns given smoothly declining aggregate relative risk aversion, but unstable characteristics given strong variations in the decline of relative risk aversion. In the latter case, the model indicates strong variability in expected stock returns, volatility, and in serial correlation of stock returns. It even explains crashes without significant fundamental news for which 
Shiller [1] provides evidence. Temporary illiquidity of stock markets may also contribute to financial instability. This makes it difficult to distinguish pricing effects of liquidity and of risk aversion. The current crisis illustrates this problem. Our model is based on a perfect capital market in which illiquidity problems do not exist.

To present our case of instability, we use a simple model of a perfect, competitive financial market similar to Wang [2], Campbell and Cochrane [3], and Chan and Kogan [4] in which the dividend on the market portfolio is governed by a geometric Brownian motion and the price of the market portfolio equals the present value of these dividends. Aggregate relative risk aversion depends on the equilibrium allocation of consumption and the relative risk aversion levels of the various investors. The level and variation of aggregate relative risk aversion are controversial. Defining aggregate relative risk aversion as the negative elasticity of the stochastic discount factor with respect to market wealth, empirical studies estimate its level using option prices. The empirical results documented in Aït-Sahalia and Lo [5], Jackwerth [6], and Rosenberg and Engle [7] suggest extreme bounds for aggregate relative risk aversion. Aït-Sahalia and Lo [5], for example, document levels up to 60 for S\&P 500 index values about 15 percent below the current future price. They conclude that declining aggregate relative risk aversion appears to be more realistic than constant aggregate relative risk aversion (Assuming constant aggregate relative risk aversion, Bliss and Panigirtzoglou [8] estimate aggregate relative risk aversion levels between 1.97 and 9.52. They find that risk aversion declines with the forecast horizon and with the level of volatility. Analyzing the cross-section of industry portfolios Dittmar [9] also provides evidence against constant aggregate relative risk aversion.). Little is known on the level of aggregate relative risk aversion for index values more than 15 percent above or below the current value and the empirical estimates are subject to various methodological concerns (see $[8,10])$.

The first important result in this paper generalises the result of Benninga and Mayshar [11]. Declining aggregate relative risk aversion not only holds if every individual has constant relative risk aversion but also is likely if individual relative risk aversion is not constant. Since the aggregate dividend is exogenously given, but prices are not, we define aggregate relative risk aversion as the negative elasticity of the stochastic discount factor with respect to the dividend. In an intertemporal model this allows us to characterize aggregate risk preferences independently of endogenous asset prices. Moreover, we show that declining relative risk aversion is stable over time, in contrast to increasing relative risk aversion.

If aggregate relative risk aversion is constant, then it is well known that under some additional assumptions the market return is identically and independently distributed. If, however, aggregate relative risk aversion declines with increasing dividend, then an increase in the dividend leads to an overproportional price increase because the risk premium declines. This implies variability in the expected stock return and volatility. The less stable these parameters are, the more financial instability is induced. This instability depends on the instability in the decline in aggregate relative risk aversion. If it declines rapidly (slowly) in some dividend range, then the risk premium declines strongly (slowly) in this range so that the price of the market portfolio increases rapidly (slowly) given a small increase in dividends. Conversely, a small decline in dividends together with a strong increase in aggregate relative risk aversion leads to a strong price decline, similar to a crash. If the dividend happens to first increase and then to decline, then we may observe a stock market movement which resembles a bubble that bursts.

Since the decline pattern in aggregate relative risk aversion is crucial for financial stability, the paper analyzes the determinants of this pattern. Suppose that each investor has constant relative risk aversion. If the level of relative risk aversion of investors is uniformly 
distributed across some range and these investors have similar endowments, then aggregate relative risk aversion smoothly declines. Hence stock return characteristics are fairly stable. If, however, endowments are concentrated at investors with high and at those with low levels of relative risk aversion, then aggregate relative risk aversion declines rapidly in some dividend range. In this case, stock return characteristics are quite unstable.

The decline in aggregate relative risk-aversion is driven by the "variance of the inverse levels of relative risk aversion of investors" in which the weights are not probabilities, but the fractions of aggregate consumption of the investors which add up to 1 . In equilibrium, these fractions reflect differences in relative risk aversion and in the endowments of investors. If this "variance" varies little with aggregate dividend, then the market is rather stable. If it varies strongly, then it induces financial instability.

These important results are new as shown by a brief discussion of the theoretical asset pricing literature. For finite horizon models it is known from Bick [12] and Franke et al. [13] that if the price of the market portfolio is governed by a geometric Brownian motion as in the Black and Scholes [14] model, then aggregate relative risk aversion is constant. Stapleton and Subrahmanyam [15] assume that the dividend process is governed by a geometric (arithmetic) Brownian motion. They show that if aggregate relative risk aversion (absolute risk aversion) is constant, the forward price is governed by a geometric (arithmetic) Brownian motion. Wang [2] analyzes the term structure of interest rates in an economy with investors who display constant relative risk aversion, but at different levels. Campbell and Cochrane [3] analyze a similar economy, but they assume a representative investor whose utility depends on current and past consumption (habit) so that it is path-dependent. This allows them to explain return predictability and excess volatility. Chan and Kogan [4] combine the setup of Wang [2] and that of Campbell and Cochrane [3]. Their economy is populated with constant relative risk averse investors whose level of risk aversion differs and whose utility depends on aggregate consumption scaled by a weighted geometric average of past aggregate consumption. This feature again implies path-dependence of the utility function. Gomes and Michaelidis [16] analyze asset pricing with heterogeneous agents in incomplete markets with borrowing constraints. Brennan et al. [17] and Brennan and Xia [18] emphasize the importance of a time-varying investment opportunity set to explain predictability of asset returns. Our results depend neither on path-dependent utility functions nor on learning.

The remainder of the paper is organized as follows. In Section 2 the model is introduced and declining aggregate relative risk aversion is shown to be the normal case. Moreover, the pattern of decline in aggregate relative risk aversion is analyzed. In Section 3, instability in expected excess returns, volatility, and autocorrelation of returns is related to instability of the decline in aggregate relative risk aversion. Section 4 discusses conditions for stock market crashes. In Section 5 an analytic formula for the price of the market portfolio is presented together with simulations illustrating the previous results. Section 6 concludes.

\section{Aggregate Relative Risk Aversion}

\subsection{The Economic Setting}

Our model setup is close to Wang [2]. There exists a continuous time-pure exchange economy with a perfect and complete market. At each date $\tau$, aggregate consumption equals the dividend on the market portfolio $D_{\tau}$. The aggregate dividend is the only exogenous risk factor in the model. All agents have homogeneous and rational expectations, but different utility functions. 
Each investor, indexed by $i=1, \ldots, n$, has a time-independent von NeumannMorgenstern utility function according to which she optimizes her consumption at each date. Many people use standard time-additive utility. Then, in equilibrium, precautionary savings can force the risk free rate to be strongly negative. This can lead to infinite stock prices in an infinite horizon equilibrium model. Even if stock prices remain finite, the variation in the risk free rate can lead to a situation in which an increase in the aggregate dividend triggers a strong decline in the price of the market portfolio. Since (real) risk free rates vary little in the real world, we prefer a model in which the real risk free rate is constant.

There are different approaches to justify a constant risk free rate. Campbell and Cochrane [3] assume a risk-free production technology with constant returns to scale which is always in use. Another approach is to separate relative risk aversion and intertemporal elasticity of substitution, as suggested by Kreps and Porteus [19] and Epstein and Zin [20]. To simplify things, assume that the intertemporal elasticity of substitution is infinite for every investor. Hence the marginal rate of substitution for risk free claims is a constant which equals the investor's gross time preference rate. This rate is assumed to be the same for all investors and constant over time. Hence it equals the risk free interest rate which, therefore, is constant. The drawback of this approach is that the investor is indifferent to the intertemporal allocation of her initial endowment, which, however, matters for the intertemporal equilibrium. This gap can be closed by a social planner who determines the intertemporal allocation. If the social planner is interested in maintaining social stability over time, then he attaches constant weights to all investors over time. This will be assumed in order to rule out instability driven by changing weights. Therefore, we obtain a timehomogeneous forward pricing kernel (In a complete market with investors maximizing expected time-additive utility, the Lagrange-multiplier of the budget constraint is timehomogeneous for each investor. Therefore their sharing of the aggregate dividend is timehomogeneous, as it is in the social planner model with constant weights allocated to investors. This implies a time-homogeneous forward pricing kernel.). The forward pricing kernel equals the spot pricing kernel excluding risk free discounting. The spot pricing kernel is the function relating the stochastic discount factor to the aggregate dividend. Hence our model implies that the spot pricing kernel is also time-homogeneous except for the discounting.

\subsection{Investor Heterogeneity and Aggregate Relative Risk Aversion}

With risk aversion, the stochastic discount factor is declining in some aggregate variable like wealth or aggregate consumption. The negative elasticity of the discount factor with respect to this variable defines aggregate relative risk aversion (RRA). In our model this variable is the dividend of the market portfolio. We first show that declining aggregate RRA is the normal case. Benninga and Mayshar [11] proved the decline in a one period-model assuming that every investor has constant relative risk aversion, but levels differ across investors.

Let $x_{i}\left(D_{\tau}\right)$ denote the optimal consumption of investor $i$ at date $\tau$ as a function of aggregate consumption $D_{\tau}$ and $\alpha_{i}\left(D_{\tau}\right)=x_{i}\left(D_{\tau}\right) / D_{\tau}$ her share of consumption. Then $\sum_{i} \alpha_{i}\left(D_{\tau}\right)=1$ for every level of aggregate consumption. As shown by Benninga and Mayshar [11], in equilibrium aggregate RRA $\eta_{M}\left(D_{\tau}\right)$ is related to the investors' RRA by the harmonic mean:

$$
\frac{1}{\eta_{M}}\left(D_{\tau}\right)=\sum_{i}\left(\frac{1}{\eta_{i}\left(x_{i}\right)}\right) \alpha_{i}\left(D_{\tau}\right)
$$


$\eta_{i}\left(x_{i}\right)$ is investor $i$ 's RRA given her consumption $x_{i}$. In order to find out whether aggregate RRA declines in aggregate consumption $D_{\tau}$, we differentiate (2.1) with respect to $D_{\tau}$. As shown in the appendix, we obtain the following result.

Proposition 2.1. The elasticity of aggregate $R R A$ with respect to the aggregate dividend is

$$
\frac{\partial \ln \eta_{M}\left(D_{\tau}\right)}{\partial \ln D_{\tau}}=D_{\tau} \sum_{i} \frac{\eta_{i}^{\prime}\left(x_{i}\right)}{\eta_{i}\left(x_{i}\right)}\left[\frac{\alpha_{i}\left(D_{\tau}\right)}{\eta_{i}\left(x_{i}\right)} \eta_{M}\left(D_{\tau}\right)\right]^{2}-\sum_{i} \alpha_{i}\left(D_{\tau}\right)\left[\frac{\eta_{M}\left(D_{\tau}\right)}{\eta_{i}\left(x_{i}\right)}-1\right]^{2}
$$

The proposition shows that in equilibrium the elasticity of aggregate RRA with respect to the aggregate dividend is the difference between two terms, the first being the sum of weighted growth rates of individual RRA, the second being a pseudovariance of the inverse individual levels of RRA standardized to an expectation of 1 . If every investor has a positive share of consumption $\alpha_{i}\left(D_{\tau}\right)$, then the last term in (2.2) has the properties of a variance term. The more heterogeneous agents are in their preferences and, hence, in their equilibrium levels of RRA, the higher is this pseudovariance. It depends on the equilibrium allocation of consumption since the shares $\alpha_{i}\left(D_{\tau}\right)$ and the individual RRA $\eta_{i}\left(x_{i}\right)$ are endogenous.

Hence, as shown by Benninga and Mayshar [11], aggregate RRA is declining if every agent has constant RRA, that is, if $\eta_{i}^{\prime}\left(x_{i}\right)=0$. Now suppose $\eta_{i}^{\prime}\left(x_{i}\right) \neq 0$. Then the first term on the right-hand side of (2.2) multiplies the individual RRA growth rate $\eta_{i}^{\prime}\left(x_{i}\right) / \eta_{i}\left(x_{i}\right)$ by $z_{i}^{2} \equiv\left[\alpha_{i}\left(D_{\tau}\right) \eta_{M}\left(D_{\tau}\right) / \eta_{i}\left(x_{i}\right)\right]^{2}$. Note that $\sum_{i} z_{i}=1$, by (2.1). Hence if there are many investors, each having a positive consumption share, then the average $z_{i}$ will be very small. This holds, a fortiori, for $z_{i}^{2}$. Therefore if there are investors with increasing, with constant, and with declining RRA, then the first term on the right-hand side is likely to be close to zero while the positive second term is subtracted. The second term tends to be higher, the more heterogeneous investor preferences are (The second term approaches zero if one investor buys a very large fraction of the aggregate dividend and the other investors buy very little. This can happen if the aggregate dividend is very low or very high and marginal utility of consumption of the first investor relative to that of every other investor goes to infinity for very low, respectively, very high levels of consumption.). Since this heterogeneity appears to be strong in reality, we conclude that aggregate RRA is likely to decline.

The intuition for this result is the following. Given an optimal allocation of claims, a highly risk averse investor $i$ tends to buy claims $x_{i}\left(D_{\tau}\right)$ which increase only little with aggregate dividend $D_{\tau}$. Her demand curve $x_{i}\left(D_{\tau}\right)$ is rather flat. Hence her share $\alpha_{i}\left(D_{\tau}\right)=$ $x_{i}\left(D_{\tau}\right) / D_{\tau}$ tends to be high (low) when $D_{\tau}$ is low (high). The opposite is true of an investor with low RRA. Therefore in the low dividend states the highly risk averse investors dominate the market so that aggregate RRA turns out to be high. In the high dividend states low risk averse investors dominate the market so that aggregate RRA turns out to be low. Thus, aggregate RRA tends to decline with increasing dividend.

Next we analyze the intertemporal properties of aggregate RRA. The following proposition reinforces our view that declining aggregate RRA is the normal case. Technically, aggregate RRA is given by $\eta_{t}^{\Phi, D}$, the negative elasticity of the pricing kernel with respect to the dividend $D_{t}$. The forward date $t$-pricing kernel for claims contingent on some state at date $s$ is denoted by $\Phi_{t, s}$. In an arbitrage-free, complete market this function is unique. Noarbitrage also implies that $\Phi_{0, t}$ is a martingale and $\Phi_{t, s}=\Phi_{0, s} / \Phi_{0, t}$. Since the dividend is the only exogenous risk factor in the market, $\Phi_{0, t}$ can be characterized as a function of the dividend. The dividend or aggregate consumption is governed by an exogenous diffusion 
process with nonaccelerating growth rates, if $\partial^{2} \ln D_{s} / \partial \ln D_{t}^{2} \leq 0$, for $s>t$. This appears as a rather weak condition on the behavior of aggregate consumption. The geometric Brownian motion which is a widely used model for aggregate consumption, for example, is consistent with this assumption. For this setting we obtain the following.

Proposition 2.2. Suppose that aggregate consumption $D_{\tau}$ is governed by a diffusion process with nonaccelerating growth rates. Then declining aggregate RRA at some date s implies declining aggregate RRA at every preceding date $t$.

This proposition is proved in the appendix. It shows that for declining aggregate RRA at some date it suffices that there exists some future date with declining aggregate RRA. Conversely, increasing aggregate RRA at some date does not imply increasing aggregate RRA at all preceding dates, as can be seen from the appendix. Hence, increasing aggregate RRA is not a time-invariant property, in contrast to declining aggregate RRA.

Propositions 2.1 and 2.2 show that declining aggregate RRA is likely to hold. On the empirical side, Aït-Sahalia and Lo [5] support declining aggregate RRA. Also the overpricing of out-of-the-money put options (see, e.g., $[6,21]$ ) makes a strong case for declining aggregate RRA. Therefore the rest of the paper is based on declining aggregate RRA.

\subsection{Instability of the Decline in Aggregate Relative Risk Aversion}

Next we discuss whether aggregate RRA is declining smoothly or not. To simplify the discussion, consider an economy in which all investors have constant RRA. Then the first term in (2.2) disappears. Moreover, all consumption shares are positive. This allows us to use the pseudovariance of inverse levels of RRA as a measure of investor heterogeneity. By (2.2), this variance equals the negative elasticity of aggregate RRA with respect to the aggregate dividend. This measure of heterogeneity depends on the RRA levels of all investors and on their consumption shares, which, in turn, depend on the aggregate dividend. Consider an economy in which the highest level of RRA is $\eta_{1}$, and the lowest is $\eta_{n}$. Then, as shown by Benninga and Mayshar [11], for a very low aggregate dividend the consumption share of the most risk averse agents approaches 1 so that aggregate RRA approaches $\eta_{1}$. For very high dividends, the consumption share of the least risk averse agents approaches 1 so that aggregate RRA approaches $\eta_{n}$. Aggregate RRA is declining everywhere. The instability of the financial market will be shown to depend on the instability in the decline of aggregate RRA. This decline can be measured by $\left|\partial \ln \eta_{M} / \partial \ln D_{\tau}\right|$, that is, the negative elasticity of aggregate RRA with respect to the dividend. Proposition 2.3 provides some insights into this elasticity.

Proposition 2.3. Consider an equilibrium with investors $i(i=1, \ldots, n)$, ordered by declining level of constant $R R A, \eta_{1} \geq \eta_{2} \geq \cdots \geq \eta_{n}$ with $\eta_{1}>\eta_{n}$.

(a) The elasticity of aggregate $R R A$ with respect to the aggregate dividend is the highest when

(i) each investor has either $R R A \eta_{1}$ or $\eta_{n}$

(ii) the consumption share of investors with $R R A \eta_{1}$ equals $\eta_{1} /\left(\eta_{1}+\eta_{2}\right)$.

Then aggregate RRA equals the mean $\left(\eta_{1}+\eta_{n}\right) / 2$ and the elasticity of aggregate $R R A$ with respect to the aggregate dividend equals $(1 / 4)\left(\eta_{n} / \eta_{1}\right)\left(1+\left(\eta_{1} / \eta_{n}\right)\right)^{2}-1$.

(b) The elasticity of aggregate $R R A$ with respect to the aggregate dividend approaches 0 for very low and very high dividend levels. 


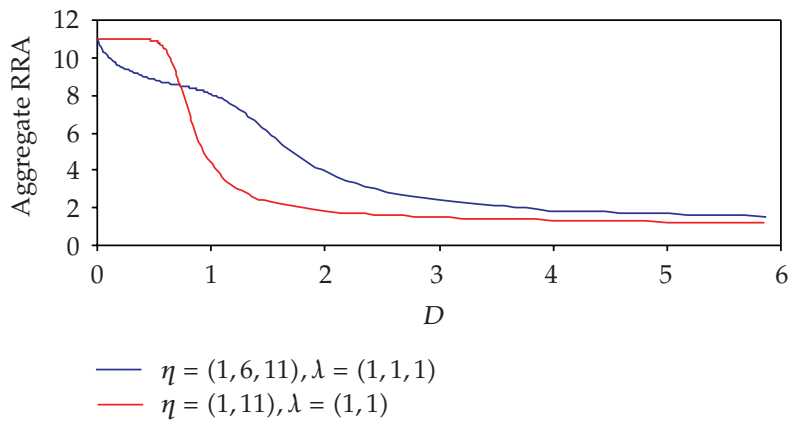

Figure 1: Aggregate relative risk aversion for two and three investor groups as a function of the aggregate dividend $D$.

Proposition 2.3(a) is proved in the appendix. Proposition 2.3(b) follows because the consumption share of the most (least) risk averse investor approaches 1 for very low (high) dividend levels. Hence the pseudovariance of inverse RRA approaches 0. Therefore the maximal pseudovariance indicates the level of instability in aggregate RRA.

The pseudovariance $\left|\partial \ln \eta_{M} / \partial \ln D_{\tau}\right|$ is maximal when each investor has the highest or lowest possible RRA, and the most risk averse investors consume the fraction $\eta_{1} /\left(\eta_{1}+\eta_{n}\right)$. To illustrate, if $\eta_{1}=2$ and $\eta_{n}=1$, then aggregate RRA is 1.5 and the pseudovariance is $1 / 8$. If $\eta_{1}=19$ and $\eta_{n}=1$, then aggregate RRA is 10 and the pseudovariance is 4.26 . Both values are much higher.The maximal pseudovariance depends only on the ratio $\eta_{1} / \eta_{n}$, not on the initial endowments of both investor groups. But the dividend level at which the pseudovariance is highest, increases with the initial endowment of the most risk averse investors. This follows because a higher endowment raises the consumption share of these investors at every dividend level and this consumption share monotonically declines in the dividend.

Retaining the same range $\left[\eta_{n}, \eta_{1}\right]$, the maximal pseudovariance is smaller at the same aggregate RRA when there are also investors with intermediate levels of RRA and substantial consumption shares. As in Proposition 2.3, let investor $i$ have a consumption share $\eta_{i} / \sum_{j} \eta_{j}$. Then aggregate RRA equals the mean $(1 / n) \sum_{j} \eta_{j}$, and the pseudovariance is $(1 / n) \sum_{i}\left(\eta_{M} / \eta_{i}\right)-1$. For $n \rightarrow \infty$ and a uniform distribution of $\eta$ across the range $[\eta, \bar{\eta}]$ the maximal pseudovariance is $(1 / 2) \ln (\bar{\eta} / \eta)(\eta+\bar{\eta}) /(\bar{\eta}-\eta)-1$. Expanding the examples above, consider three investors with $\eta_{1}=2, \bar{\eta}_{2}=1.5$, and $\bar{\eta}_{3}=1$. Then for consumption shares $\eta_{i} / \sum_{j} \eta_{j}$, aggregate RRA is 1.5 and the pseudovariance is $(2 / 3)(1 / 8)$. If $\eta_{1}=19, \eta_{2}=10$, and $\eta_{3}=1$, then aggregate RRA is 10 and the pseudovariance is $2.84=(2 / 3) 4.26$. In the limit for $n \rightarrow \infty$, at the same level of aggregate RRA, the maximal pseudovariance equals $(1 / 2)(\ln 19) 20 / 18-1=0.64$. This is a small value indicating low instability.

Summarizing, instability in the decline of aggregate RRA is strong if a large fraction of investors buys almost only risk-free assets and the other investors buy only stocks. If there are many investors mixing bonds and stocks in varying proportions, then the decline of aggregate RRA is rather stable.

Figure 1 illustrates this for cases of 2 and 3 investors. In case (a) $\eta_{1}=11$ and $\eta_{2}=1$ with $\lambda_{1}=\lambda_{2}$, and in case (b), there exists an additional investor with an average level of RRA, $\eta_{1}=11, \eta_{2}=6, \eta_{3}=1$ with $\lambda_{1}=\lambda_{2}=\lambda_{3}$. $\lambda_{i}$ is investor $i$ 's expected marginal utility in equilibrium. $\lambda_{i}$ is higher, the smaller the investor's endowment is. Equivalently, $1 / \lambda_{i}$ can be interpreted as the weight allocated to investor $i$ by a social planner who allocates the 


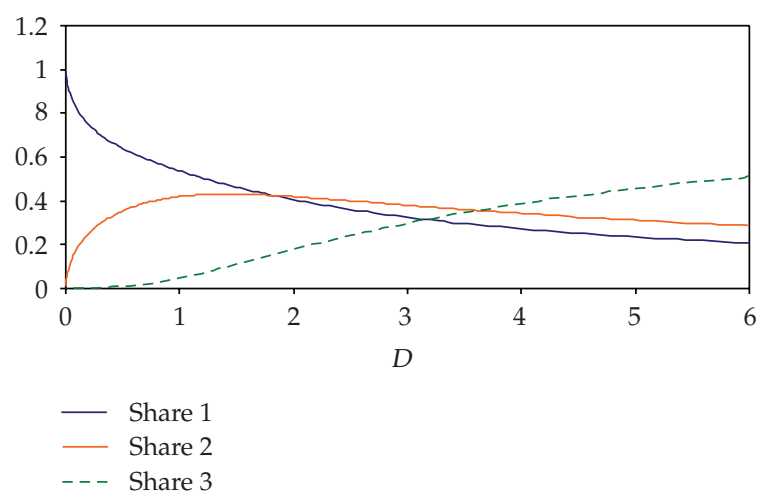

(a)

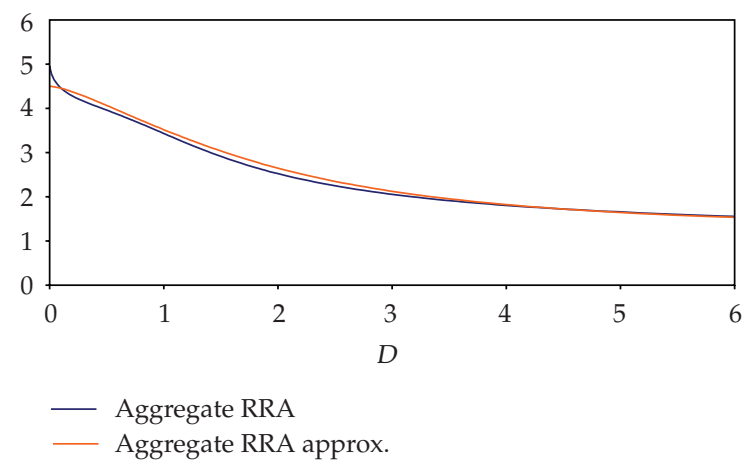

(b)

Figure 2: (a) shows the consumption shares of the three investors as a function of aggregate dividend. (b) shows the implied aggregate RRA as a function of aggregate dividend. The approximation will be used later in the simulation. $(\eta)=(5 ; 3 ; 1)$ and $1 / \lambda=(1 ; 3 / 5 ; 1)$.

aggregate dividend $D$ to the investors so as to maximize their weighted expected utility. The black curve depicts aggregate RRA for case (a), the grey curve for case (b). In case (a), aggregate RRA is almost constant at the level 11 for dividends up to 0.6 units, then strongly declines in the dividend range $(0.6,1)$, and then gradually approaches the lower bound 1 . In case $(b)$, aggregate RRA declines smoothly over the dividend range $(0,2.5)$ indicating more stability.

To provide further insight into aggregate RRA patterns, we present three more examples. Assume that there are three investor groups (for short, investors) with different levels of constant relative risk aversion. $\left(\eta_{1}, \eta_{2}, \eta_{3}\right)$ denotes the vector of these levels. Sensitivity of the results with respect to $\left(\lambda_{1}, \lambda_{2}, \lambda_{3}\right)$ will be analyzed, too. To determine the values for the risk aversion parameters we refer to recent empirical estimates of aggregate RRA implied by option prices, but stick to relatively conservative specifications.

Figures 2 to 4 illustrate the simulation results. The upper graph shows the shares of claims bought by the three investors as a function of the aggregate dividend. These shares always add up to 1 . The lower graph shows the implied aggregate RRA as a function of the aggregate dividend (fat curve) and an approximation of the fat curve (thin curve) which is used later. Note that the scale of $D$, the aggregate supply of claims, is irrelevant since all investors have constant RRA. 


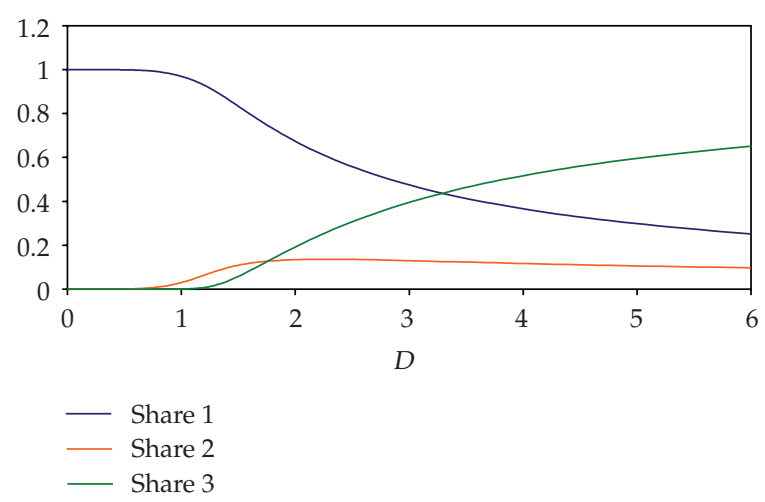

(a)

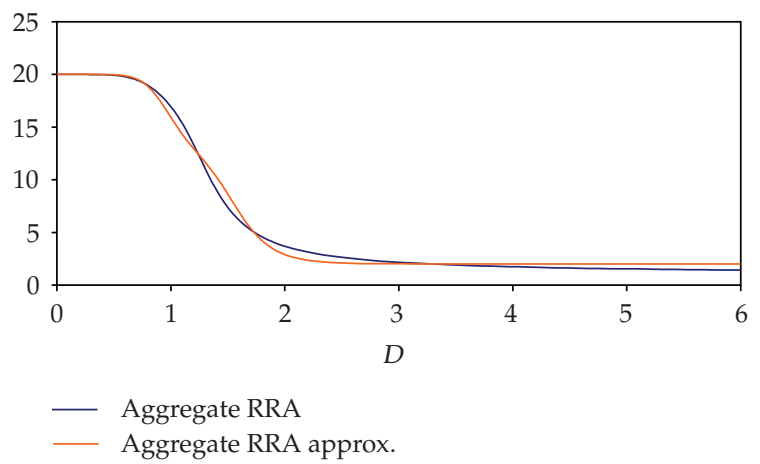

(b)

Figure $3:(\eta)=(20 ; 3 ; 1)$ and $1 / \lambda=\left(10^{-3} ; 20 ; 1\right)$.

Figure 2 may be viewed as the "normal" case. The three investors have RRA levels $(5 ; 3 ; 1)$. The weights $(1 / \lambda)$ are given by the vector $(1 ; 3 / 5 ; 1)$. As indicated in the upper graph, given a very low aggregate dividend, the most risk averse investor 1 buys almost all available claims, but her share declines quickly since, first, investor 2 with RRA 3 quickly raises her share and, second, the least risk averse investor also increases her share gradually. The lower graph shows that aggregate RRA is basically a smoothly declining convex curve. Hence, in this setting there is little instability.

In Figure 3 we raise investor 1's RRA from 5 to 20 so that $(\eta)=(20 ; 3 ; 1) .(1 / \lambda)=$ $\left(10^{-3} ; 20 ; 1\right)$ so that the expected marginal utility of investor 1 is very high indicating a small endowment. Yet the upper graph in Figure 3 shows that she buys almost all claims as long as the supply of claims stays below 1 . The second and third investors come into play at higher supply levels. Therefore, aggregate RRA stays almost constant at a level of 20 for the entire $(0 ; 1)$ range of claims supply. Then it declines sharply in the range $(1 ; 1.5)$ and thereafter slowly approaches level 1, the RRA of the least risk averse investor. The sharp decline in aggregate RRA paves the ground for a crash.

Consider a third example in Figure 4. Now there exist two investors with high RRA 20 and 18 , respectively, and one investor with RRA $1 ;(\eta)=(20 ; 18 ; 1)$ and $(1 / \lambda)=(10 ; 6 ; 1)$. Again, the decline in aggregate RRA is very unstable.

How robust are these results? Additional simulations indicate several properties. First, if as in Figure 4, there are 2 investors such that their levels of RRA are higher than twice the 


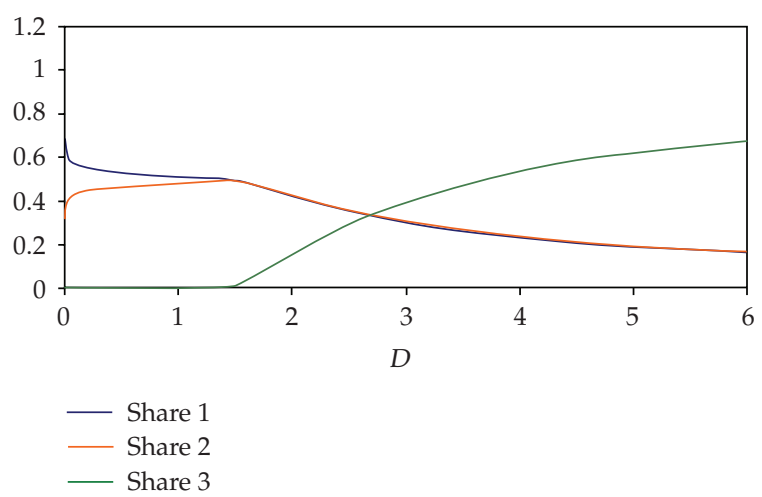

(a)

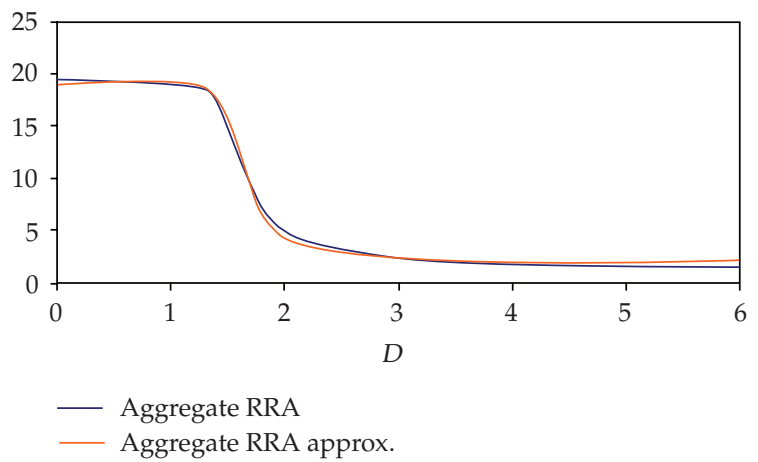

(b)

Figure $4:(\eta)=(20 ; 18 ; 1)$ and $(1 / \lambda)=(10 ; 6 ; 1)$.

level of the third investor, then the aggregate RRA curve is similar to that in Figure 4. Second, if the weights $(1 / \lambda)$ for the three investors are changed, then the shape of the aggregate RRA curve remains similar, but the low dividend range with almost constant aggregate RRA will be shorter or longer depending on the endowment of the most risk averse investors. Third, if there are many investors instead of one with the same constant RRA $\eta$, this has no effect on aggregate RRA as long as the sum of the $\lambda^{1 / \eta}$ across these investors stays the same. This follows because all investors with the same RRA buy the same portfolio of claims up to multiplicative factors reflecting the levels of their initial endowments.

Therefore, the shape of aggregate RRA shown in Figures 3 and 4 appears to be robust to a wide set of parameter changes. The crucial condition for a sharp decline of aggregate RRA in some range of the supply of claims appears to be that the investors can be split into two groups, the first having high levels of RRA and the second having low levels of RRA such that the high levels exceed twice the low levels.

\section{Instability of Excess Return and Volatility}

In this section we show that instability in the decline of aggregate RRA induces financial instability, that is, strong variability in the characteristics of the market portfolio return. We investigate the pricing of the market portfolio in a perfect and complete capital market. We 
consider a continuous time economy with an infinite horizon. The instantaneous risk-free rate $r_{f}$ equals the time preference of investors which is exogenously given and nonrandom. As in many other papers, the market portfolio pays an exogenously given dividend stream which is governed by a geometric Brownian motion:

$$
d D_{t}=\mu_{D} D_{t} d t+\sigma_{D} D_{t} d W_{t}, \quad 0 \leqslant t<\infty,
$$

where the instantaneous drift $\mu_{D}$ and the instantaneous volatility $\sigma_{D}$ are assumed constant. $W_{t}$ is a one-dimensional standard Brownian motion and the initial dividend $D_{0}$ is positive. This represents a simple setting with the dividend being the only risk factor. The price of the market portfolio at date $t, S_{t}$, is the present value of all future dividends:

$$
S_{t}=E\left(\int_{t}^{\infty} \exp \left(-r_{f}(s-t)\right) D_{s} \Phi_{t, s} d s \mid D_{t}\right)
$$

This price is finite given a sufficiently high risk-free rate and aggregate risk aversion. Since the dividend is the only risk factor in the market, the pricing kernel $\Phi_{0, t}$ can be characterized by

$$
\begin{gathered}
d \Phi_{0, t}=-\eta_{t}^{\Phi, D} \sigma_{D} \Phi_{0, t} d W_{t}, \\
\Phi_{0,0}=1 .
\end{gathered}
$$

Hence $\Phi_{0, t}>0$ so that the market is arbitrage-free. As aggregate RRA $\eta_{t}^{\Phi, D}$ is timehomogeneous, the asset price $S_{t}$ is a time-homogeneous function of the dividend at date $t$ and can be characterized by the following stochastic differential equation:

$$
d S_{t}=\underbrace{\eta_{t}^{\Phi, D} \eta_{t}^{S, D} \sigma_{D}^{2} S_{t}-D_{t}+r_{f} S_{t}}_{=\mu_{S}\left(S_{t}\right) S_{t}} d t+\underbrace{\eta_{t}^{S, D} \sigma_{D} S_{t}}_{=\Sigma_{S}\left(S_{t}\right) S_{t}} d W_{t} .
$$

$\mu_{S}\left(S_{t}\right)$ denotes the instantaneous drift which equals the expected instantaneous excess return plus the risk-free rate $r_{f}$. $\Sigma_{S}\left(S_{t}\right)$ denotes the instantaneous volatility, and $\eta_{t}^{S, D}$ the elasticity of the asset price $S_{t}$ with respect to the dividend $D_{t}$. Both, volatility and drift depend in general on the asset price $S_{t}$.

One measure of financial instability is the variability in the elasticity of the asset price with respect to the dividend. If this elasticity is always equal to 1 , then the asset price follows a geometric Brownian motion since the dividend is governed by a geometric Brownian motion. If the elasticity is higher than 1, then the spot price overreacts compared to a geometric Brownian motion. As long as the extent of overreaction is constant, the market is said to be stable. The following proposition establishes the relationship between overreaction and aggregate RRA.

Proposition 3.1 (Overreaction). Assume that at each date aggregate RRA is declining in the dividend and that the dividend is governed by a geometric Brownian motion with constant 
instantaneous volatility and constant instantaneous drift. Then the elasticity of the asset price with respect to the dividend is higher than 1, that is,

$$
\eta_{t}^{S, D}=1-\frac{1}{S_{t}} \int_{t}^{\infty} \frac{\operatorname{cov}^{\tilde{P}}\left(D_{s}, \eta_{s}^{\Phi, D} \mid D_{t}\right)}{\exp \left(r_{f}(s-t)\right)} d s>1
$$

Hence the variability in $\eta_{t}^{S, D}$ is driven by the variability in the covariance between the aggregate dividend and aggregate $R R A$.

This proposition is proved in the appendix. $\operatorname{cov}^{\tilde{P}}(\cdot, \cdot)$ denotes the covariance under the risk adjusted probability measure using $\Phi_{t s}\left(D_{s}\right) / E\left(\Phi_{t s}\left(D_{s}\right) \mid D_{t}\right)$ for risk adjustment. This covariance is negative (positive) for declining (increasing) aggregate RRA. To get the intuition for the overreaction, think about aggregate RRA in terms of a representative investor. A representative investor with decreasing RRA requires a lower excess return for the same risk, the wealthier she is, that is, the higher the dividend is. Compared to an investor with constant RRA, her required risk premium decreases, the wealthier she is. Hence, the price she is willing to pay for the asset increases with increasing dividend more than under constant RRA. Thus, with declining aggregate RRA an increase in the dividend induces a decline in the required risk premium which reinforces the purely fundamental increase of the asset price so that the asset price overreacts compared to constant aggregate RRA.

As (3.5) shows, the extent of overreaction, measured by $\eta_{t}^{S, D}-1$, depends on the present value of negative covariances between the dividend and aggregate RRA. If aggregate RRA declines slowly in the aggregate dividend, then the covariances are close to zero so that $\eta_{t}^{S, D}$ is only slightly above 1 . If there exists a dividend range in which aggregate RRA strongly declines, then in this range $\eta_{t}^{S, D}$ is much higher. Hence financial instability increases with the instability in the decline of aggregate RRA.

To draw conclusions about the behavior of excess returns we derive the behavior of the total return index (performance index) $V_{t}$. Since the total return index includes the reinvested dividend payments, its return minus the risk-free rate is the excess return that we are interested in:

$$
\frac{d V_{t}}{V_{t}}-r_{f} d t=\frac{d S_{t}}{S_{t}}+\frac{D_{t}}{S_{t}} d t-r_{f} d t
$$

Note that $V_{t}=\alpha_{t} S_{t}$ with $\alpha_{t}$ being independent of $D_{t}$. Therefore $\partial \ln V_{t} / \partial \ln D_{t} \equiv \eta_{t}^{V, D}=\eta_{t}^{S, D} \equiv$ $\partial \ln S_{t} / \partial \ln D_{t}$. This implies that Proposition 3.1 holds equally for the elasticities $\eta_{t}^{S, D}$ and $\eta_{t}^{V, D}$.

Overreaction translates into an increase in the instantaneous volatility of returns as the instantaneous volatility of the total return index is the product $\Sigma_{V}\left(S_{t}\right)=\eta_{t}^{V, D} \sigma_{D}$. Hence the instantaneous return volatility varies more, the more the elasticity of the stock price with respect to the dividend varies, indicating more financial instability. The following proposition establishes that declining aggregate RRA raises the conditional and the unconditional variance of asset returns over finite periods. Hence, declining aggregate RRA can explain the well-documented high levels of volatility (Ghysels et al. [22] provide an extensive overview on the characteristics of return volatility.). 
Proposition 3.2 (Volatility). Suppose that at each date aggregate RRA is declining in the dividend and that the dividend is governed by a geometric Brownian motion with constant instantaneous volatility and constant instantaneous drift. Then the conditional $(\tau>t=\theta)$ and the unconditional $(\tau>t>\theta)$ variance of the total return index exceed the dividend variance, that is,

$$
\operatorname{Var}\left(\ln V_{\tau}-\ln V_{t} \mid D_{\theta}\right)>\operatorname{Var}\left(\ln D_{\tau}-\ln D_{t} \mid D_{\theta}\right)
$$

The conditional total return variance increases with overreaction $\left(\eta^{S, D}-1\right)$. Variability of overreaction leads to variability in the conditional total return variance.

Proposition 3.2 is proved in the appendix. The conditional variance $\operatorname{Var}\left(\ln V_{\tau} \mid D_{t}\right)$ exceeds the dividend variance $\operatorname{Var}\left(\ln D_{\tau} \mid D_{t}\right)$ because of overreaction. The same is true of the unconditional variance. The conditional variance $\operatorname{Var}\left(\ln V_{\tau}-\ln V_{t} \mid D_{t}\right)$ is higher, the stronger is the overreaction. If the overreaction $\left(\eta^{S, D}-1\right)$ is small everywhere, then the variance of $\ln V_{\tau}$ relative to that of $\ln D_{\tau}$ is small and does not vary much. Hence it is fairly stable. If, however, $\left(\eta^{S, D}-1\right)$ is quite high in some dividend range and small otherwise, then the variance of $\ln V_{\tau}$ is also unstable implying more financial instability. Proposition 3.2 assumes declining aggregate RRA. It does not hold in an analogous manner for increasing aggregate RRA.

Does overreaction imply that the expected market return depends on the aggregate dividend? (For an overview on return predictability and return volatility as well as a discussion of the methodological problems, see Ang and Bekaert [23].) First, notice that the instantaneous drift of the total return index $\mu_{V}\left(S_{t}\right)$ equals the instantaneous drift of stock returns plus the dividend yield. Hence the instantaneous Sharpe ratio

$$
\frac{\mu_{V}\left(S_{t}\right)-r_{f}}{\Sigma_{V}\left(S_{t}\right)}=\frac{\mu_{S}\left(S_{t}\right)+D_{t} / S_{t}-r_{f}}{\Sigma_{S}\left(S_{t}\right)}=\eta_{t}^{\Phi, D} \sigma_{D}
$$

depends negatively on $D_{t}$ for declining aggregate RRA, $\eta_{t}^{\Phi, D}$. Therefore the Sharpe ratio can be predicted knowing the current dividend. This predictability is particularly strong if aggregate RRA declines strongly in the aggregate dividend. Hence higher instability in aggregate RRA translates into stronger predictability. The predictability of the Sharpe ratio would directly translate into predictability of excess returns if the instantaneous return volatility $\Sigma_{V}\left(S_{t}\right)$ was nonrandom. But changes in volatility might disturb this relationship, the exception being that the volatility does not increase with the dividend.

Another characteristic of the asset price process is the return autocorrelation. To analyze the serial return dependence, we consider the covariance between the excess return over the time span $[t, \tau]$, that is, $\mathrm{CER}_{t, \tau} \equiv \int_{t}^{\tau} d V_{s} / V_{s}-\int_{t}^{\tau} r_{f} d s$, and the instantaneous expected excess return at time $\tau$, that is, $\mu_{V}(\tau)-r_{f}$; see also Johnson [24].

Proposition 3.3. Suppose that at each date aggregate $R R A$ is declining in the dividend and that the dividend is governed by a geometric Brownian motion with constant instantaneous volatility and constant instantaneous drift. Then, the cumulated excess return and the instantaneous expected excess return are negatively correlated if the volatility of excess returns does not increase with the dividend (The corresponding result for increasing aggregate RRA is shown in the appendix.).

This proposition is proved in the appendix (The conditions established in Proposition 3.3 are sufficient but not necessary.). It shows that excess returns are negatively 
autocorrelated if aggregate RRA is declining, provided that the volatility of excess returns does not increase with the dividend. The intuition for the negative autocorrelation is that if past returns have been strongly positive, investors are better off implying lower aggregate RRA. Hence, the required risk premium decreases which lowers future expected excess returns. This leads to negative autocorrelation. However, Proposition 3.3 reveals that autocorrelation might be positive if the volatility of excess returns strongly increases with the dividend so that the required risk premium increases, too. This may happen if there is a dividend range in which aggregate RRA strongly declines so that the stock price strongly increases with the dividend. Thus, the sign of autocorrelation turns out to be unstable if aggregate RRA is not smoothly declining.

The level of the return autocorrelation is closely tied to the stability of the elasticity $\eta^{V, D}$. If $\eta^{V, D}$ varies only little, then the instantaneous expected excess return and the instantaneous return volatility vary only little. Hence the autocorrelation is negative and close to zero. If, however, $\eta^{V, D}$ varies a lot, due to strong variation in aggregate RRA, then autocorrelation tends to be stronger in some dividend range, but may even turn positive. Therefore financial instability can manifest in changing signs of autocorrelation.

To sum up, this section has shown that overreaction, return predictability, enlarged volatility, and autocorrelation in returns follow from declining aggregate RRA. These effects need not be stable, however. Stability depends very much on the stability of the decline in aggregate RRA. If aggregate RRA declines smoothly everywhere, then these effects are rather stable. If, however, aggregate RRA declines strongly in some dividend range and otherwise slowly, then these effects are also unstable translating into strong financial instability.

\section{Stock Market Crashes}

Our simple rational expectations model also permits an explanation of stock market crashes without advocating market imperfections or "irrational behaviour" (For an excellent overview of such models consider Brunnermeier [25].). Stock market crashes are an illustration of extreme financial instability. We define a crash as a situation in which a small decline in the fundamentals triggers a strong decline in the stock price. Conversely, a small improvement in the fundamentals may trigger a strong increase in the stock price. A bubble that bursts may be observed if a small improvement in fundamentals leading to a strong price increase is followed by a small decline in fundamentals leading to a strong price decline. Such phenomena can be explained in a perfect market with rational expectations.

A crash is based on a shift from a low-risk aversion regime to a high-risk aversion regime. To illustrate the regime shift, first, consider a market with constant aggregate RRA, $\bar{\eta}$. Then in an infinite horizon model in which the aggregate dividend follows a geometric Brownian motion, the stock price at date $t, S_{t}$, is a multiple of the dividend at date $t, S_{t}=$ $D_{t} / k$ with $k=r_{f}+\bar{\eta} \sigma_{D}^{2}-\mu_{D}$. To make things simple, suppose that $r_{f}$ equals $\mu_{D}$. Empirical estimates of the dividend volatility of the market portfolio are around 12.8 percent. Then the price dividend ratio would be around 61 for constant aggregate RRA of 1 . Now suppose that unexpectedly aggregate RRA increases from a constant level of 1 to a constant level of 10 . Then the price dividend ratio would drop to 6.1; that is, the price would drop by 90 percent. Hence the shift from the low- to the high-risk aversion regime induces a stock market crash.

The property required for a crash is that aggregate RRA stays almost constant in the range of low aggregate dividends, then drops sharply with an increase in dividends, and, again, almost stays constant in the upper range. Even though a precise characterization of the conditions implying these properties is difficult, Proposition 2.3 indicates situations 
leading to a crash. If investors have very high or very low RRA, then the maximal elasticity of aggregate RRA with respect to the dividend, $\left|\partial \ln y_{M} / \partial \ln D_{\tau}\right|$, is approximately $(1 / 4)\left(\eta_{n} / \eta_{1}\right)\left(1+\left(\eta_{1} / \eta_{n}\right)\right)^{2}-1$. Hence given a high ratio $\eta_{1} / \eta_{n}$, there exists a dividend range in which aggregate RRA strongly declines. In this dividend range a small increase in dividends starting at the low end of the range leads to a very strong price increase, while a small dividend decline starting at the high end leads to a crash. This is explained by a regime shift. There exists a range of low aggregate dividends in which the most risk averse investor group buys a high share of the available claims so that aggregate RRA approaches its high level of constant RRA. This group dominates the market in this dividend range. In the range of high dividends, this group buys a small share of the available claims so that its influence on the market disappears. In this range the least risk averse investor group dominates the market. Hence the shift from a high- to a low-risk aversion regime explains a crash.

\section{Simulation}

In this section we illustrate our results by simulating the returns of the market portfolio. First, we discuss the procedure used for simulation. Second, we present the simulation results.

\subsection{Simulation Procedure}

The simulation approximates the valuation of the market portfolio in an infinite horizon setting by a finite horizon setting with a very long horizon. The price of the market portfolio at the horizon is a function of the aggregate dividend paid at the horizon. Once the stochastic discount factor for the horizon date is known, the stochastic discount factors for the preceding dates can be derived from no-arbitrage. Therefore we only need to specify the stochastic discount factor for the horizon date. We approximate the equilibrium stochastic discount factor through a sum of power functions. Let $S_{t+h}$ be the value of the market portfolio at some horizon date $t+h$ which defines the aggregate supply of claims at that date. The discount factor, $\Phi_{t, t+h}\left(S_{t+h}\right)$, is approximated by the generalized polynomial

$$
\Phi_{t, t+h}=\frac{\sum_{i=1}^{N} \alpha_{i} S_{t+h}^{-\delta_{i}}}{E\left[\sum_{i=1}^{N} \alpha_{i} S_{t+h}^{-\delta_{i}} \mid D_{t}\right]}
$$

with $\alpha_{i}, \delta_{i} \in \mathbb{R}$. This specification is very general. Since the $\delta_{i}$ 's are not required to be integers, this approximation is at least as good as a Taylor-series approximation. For large $N$, the approximation error converges to zero. For illustration, we use polynomials with $N=3$ terms. We use again the three specifications which illustrated aggregate RRA in Section 2.3. These specifications are given in Figures 2 to 4 . Table 1 displays for each figure the parameters of the investors and the parameters $\delta_{i}$ and $\alpha_{i}$ used in the generalized polynomial.

Table 1 shows that the exponents $\delta_{1}$ and $\delta_{3}$ used in the polynomial approximation of the stochastic discount factor correspond closely to the RRA $\eta_{1}$ and $\eta_{3}$, respectively. The quality of the approximation can be seen in the lower graphs of Figures 2 to 4 depicting the equilibrium aggregate RRA (fat curve) and aggregate RRA derived from the approximation (thin curve). The approximation appears to be quite good. It could be further improved by using more than three power functions (see also [21]). Alternatively, we could choose 
a setting with more than 3 investors which would yield an equilibrium aggregate RRA indistinguishable from the thin curve.

The value of the market portfolio at the horizon is a deterministic function of the dividend paid at the horizon, $S_{t+h}=S_{t+h}\left(D_{t+h}\right)$ consistent with the infinite horizon model. In order to avoid artificial instability, we specify $S_{t+h}\left(D_{t+h}\right)$ as a function with constant elasticity, that is, $S_{t+h}=d p D_{t+h}^{\vartheta}$. dp is a kind of price dividend ratio. The exponent $\vartheta$ is greater than 1 indicating declining aggregate RRA. Analyzing the annual S\&P 500 real price and price-dividend data for the time period 1871-2002, (Source: Shiller (http://www.econ.yale.edu/ shiller/data.htm).) one finds that the price-dividend ratio is reasonably approximated by $S_{t} / A D_{t}=7.27 A D_{t}^{0.53}$ with an $R^{2}$ of almost 40 percent where $A D_{t}=12 D_{t}$ is the annual and $D_{t}$ the monthly dividend. This implies for the numerical simulation based on monthly data $S_{t+h}=325.6 D_{t+h}^{1.53}$. The real interest rate is set to 2.5 percent p.a. which is consistent with the historical average (see [18]). Consistent with the historical mean and volatility of real monthly dividend growth we choose $\sigma_{D}=0.037$ and $\mu_{D}=0.002$.

The date $t$-value of the market portfolio is given by

$$
S_{t}=\sum_{s=t}^{t+h} \exp \left(r_{f}(t-s)\right) E\left(D_{s} \Phi_{t, s} \mid D_{t}\right)+\exp \left(-r_{f} h\right) E\left(d p D_{t+h}^{\vartheta} \Phi_{t, t+h} \mid D_{t}\right)
$$

Using the stochastic discount factor polynomial, $E\left(S_{t+h} \Phi_{t, t+h} \mid D_{t}\right)$ is a weighted average of means of power functions of $S_{t+h}$. Since $S_{t+h}$ is a power function of $D_{t+h}$ and $D_{t+h}$ is lognormally distributed, $E\left(S_{t+h} \Phi_{t, t+h} \mid D_{t}\right)$ can be derived analytically. The same is true of $E\left(D_{s} \Phi_{t, s} \mid D_{t}\right)$ since $\Phi_{t, s}=E\left(\Phi_{t, t+h} \mid D_{s}\right)$ by no-arbitrage. Hence the price $S_{t}$ can be derived analytically as a function of the dividend $D_{t}$ as shown in the appendix.

We use simulation to derive the properties of the price process. In each simulation run, we generate 240 observations of the dividend process. This corresponds to 20 years of monthly data. Given a constant investment horizon of $h=240$ months, so that $t+h$ moves over time, we obtain a sequence of 240 asset prices, derived from (5.2). The initial dividend $D_{0}$ is set to 1 or 4 . For every model specification we run 1000 simulations. The parameters of every specification 1 to 3 are given in Table 1, approximating aggregate RRA in Figures 2 to 4. Since we use a very long horizon of 240 months, the impact of replacing the infinite by a finite time horizon model on our simulation results is very small. This is shown by further simulations not reported here.

\subsection{Simulation Results}

First, consider Figure 5 illustrating the relationship between the asset price and the concurrent dividend.

In the benchmark case of constant aggregate RRA the asset price increases linearly in the dividend. Thus, there is perfect financial stability. In specification 1, the rather mild decline in aggregate RRA produces a convex curve which mildly contrasts with the benchmark case, thus retaining a high level of financial stability. Specifications 2 and 3 deviate strongly from the benchmark case. For low dividends, the asset price increases very little with the dividend, then around a dividend level of 4, it increases strongly, and, thereafter, it increases almost proportionally as in the benchmark case. Hence, specifications 2 and 3 show the potential for a stock market crash. If, given specification 3 , the dividend declines from 4.3 to 3.8 , then the price of the market portfolio crashes from about 1,400 to around 260 . 
Table 1: For each figure the table shows the RRA of the three investors $(\gamma)$ and their relative expected marginal utility $\left(\lambda^{-1}\right)$. The parameters used in the polynomial approximation of the stochastic discount factor are the exponents $(\delta)$ and the weights $(\alpha)$.

\begin{tabular}{cccccccccccc}
\hline & \multicolumn{1}{c}{ Figure 1} & \multicolumn{1}{c}{ Figure 2} & \multicolumn{5}{c}{ Figure 3 } \\
\hline$\gamma_{1}$ & 5 & $\delta_{1}$ & 4.5 & $\gamma_{1}$ & 20 & $\delta_{1}$ & 20 & $\gamma_{1}$ & 20 & $\delta_{1}$ & 19 \\
$\gamma_{2}$ & 3 & $\delta_{2}$ & 3 & $\gamma_{2}$ & 3 & $\delta_{2}$ & 12 & $\gamma_{2}$ & 18 & $\delta_{2}$ & 6 \\
$\gamma_{3}$ & 1 & $\delta_{3}$ & 1.2 & $\gamma_{3}$ & 1 & $\delta_{3}$ & 2 & $\gamma_{3}$ & 1 & $\delta_{3}$ & 2 \\
\hline$\lambda_{1}^{-1}$ & 1 & $\alpha_{1}$ & 1 & $\lambda_{1}^{-1}$ & $10^{-3}$ & $\alpha_{1}$ & 1 & $\lambda_{1}^{-1}$ & 10 & $\alpha_{1}$ & 1 \\
$\lambda_{2}^{-1}$ & 0.6 & $\alpha_{2}$ & 1 & $\lambda_{2}^{-1}$ & 20 & $\alpha_{2}$ & 1 & $\lambda_{2}^{-1}$ & 6 & $\alpha_{2}$ & 0.001 \\
$\lambda_{3}^{-1}$ & 1 & $\alpha_{3}$ & 0.2 & $\lambda_{3}^{-1}$ & 1 & $\alpha_{3}$ & 0.01 & $\lambda_{3}^{-1}$ & 1 & $\alpha_{3}$ & 0.0001 \\
\hline
\end{tabular}

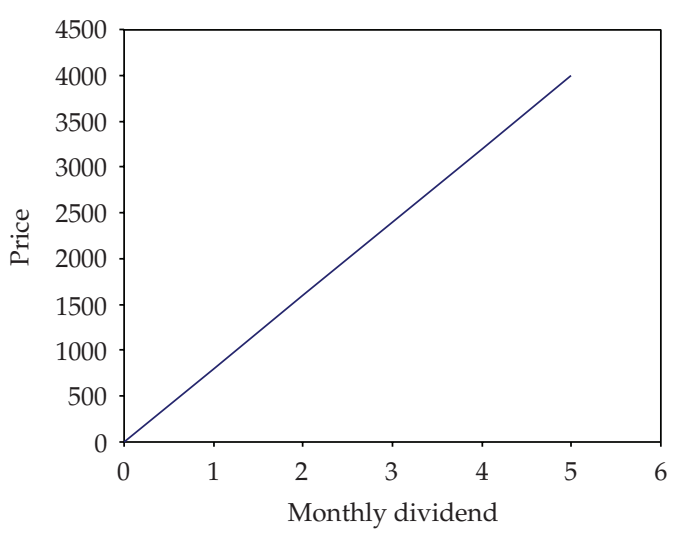

(a)

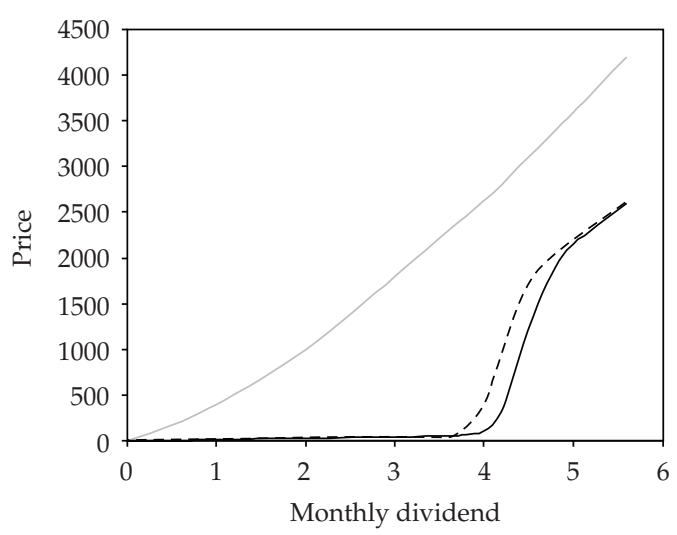

(b)

Figure 5: Asset price as a function of the concurrent monthly dividend. The figure shows for four different specifications the asset price as a function of the concurrent monthly dividend. The first graph (a) shows the benchmark case of constant aggregate RRA. The other graph shows the asset prices for declining aggregate RRA as shown in Specification 1 (gray line), Specification 2 (black line) and Specification 3 (dotted line) (Figures 2-4).

A small decline (less than 12 percent) in the dividend, the fundamental variable, triggers a very strong decline in the market value (more than 80 percent). If the dividend happens to first increase from 3.8 to 4.3 and then to fall back to 3.8 , then the asset price increases from about 260 to 1,400 and then falls back to about 260 . This can be viewed as a bubble. Technicians would call 260 a support level and 1,400 a resistance level.

The strong financial instability of specifications 2 and 3 is also illustrated by the strong variability in the elasticity of the asset price with respect to the dividend as shown in Figure 6. This elasticity varies only little with levels between 1 and 2 in specification 1 , but it increases dramatically to more than 16 in specifications 2 and 3 around a dividend level of 4 so that the local return volatility will be quite high.

Figure 5 also illustrates instability in expected asset returns. In Figure 5, the expected asset return is reflected in the slope of the asset price curve. This slope varies except for the benchmark case; its variation is particularly strong for specifications 2 and 3, due to the crash potential. Another indicator of instability is the Sharpe-ratio. The simulation shows that except for the benchmark case the monthly Sharpe-ratio declines with increasing dividend, similar to the aggregate RRA. This decline is particularly strong for specifications 2 and 3 . For specification 3 the average Sharpe-ratio is around 0.18 given an initial dividend $D_{0}=4$. For 


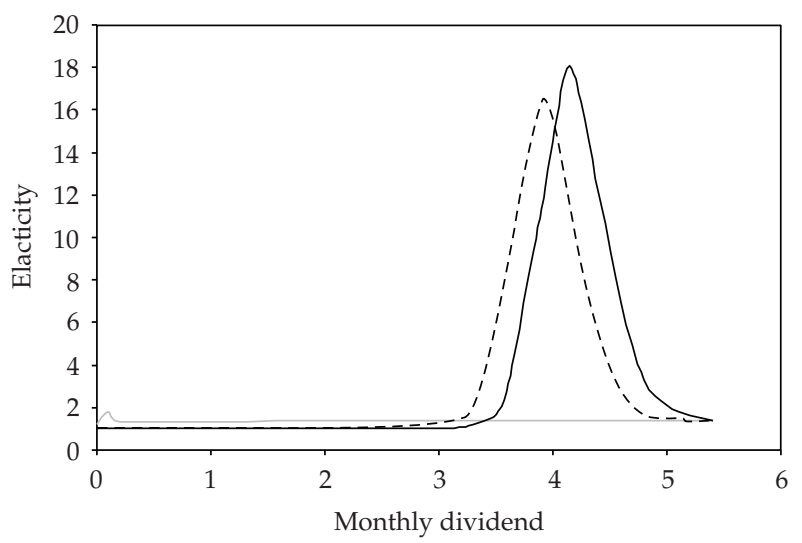

Figure 6: Elasticity of the asset price with respect to the concurrent monthly dividend. The figure shows the elasticity of the asset price with respect to the concurrent monthly dividend for declining aggregate RRA as shown in Specification 1 (gray line), Specification 2 (black line), and Specification 3 (dotted line) (Figures 2-4). The benchmark case of constant aggregate RRA (not shown in the figure) yields a constant elasticity of 1 .

Table 2: Characteristics of excess returns and return volatility. The table shows the mean annualized volatility of monthly and 4-year returns, the lag 1-serial correlation of these returns, as well as lag 1and lag 4-serial correlations in return volatility. For comparison we also show the theoretical values for a geometric Brownian motion (constant aggregate RRA). Results are shown for two different start values $\left(D_{0}=1\right.$ and $\left.D_{0}=4\right)$ of the dividend process. Specifications 1 to 3 correspond to the aggregate RRA shown in Figures 2 to 4 .

\begin{tabular}{lcccccccc}
\hline \multirow{2}{*}{ Specification } & \multicolumn{3}{c}{ Start value $D_{0}=1$} & \multicolumn{3}{c}{ Start value $D_{0}=4$} & \multirow{2}{*}{ GBM } \\
& 1 & 2 & 3 & 1 & 2 & 3 & \\
\hline Mean-annualized volatility of monthly returns & 0.167 & 0.192 & 0.201 & 0.178 & 0.843 & 0.774 & 0.128 \\
Mean-annualized volatility of 4-year returns & 0.166 & 0.168 & 0.181 & 0.177 & 0.624 & 0.583 & 0.128 \\
Mean autocorrelation (lag 1) of monthly returns & -0.002 & -0.015 & -0.011 & -0.002 & -0.028 & -0.023 & 0 \\
Mean autocorrelation (lag 1) of 4-year returns & -0.019 & -0.031 & -0.055 & -0.015 & -0.168 & -0.179 & 0 \\
Autocorrelation (lag 1) in monthly return volatility & 0.064 & 0.900 & 0.890 & 0.006 & 0.966 & 0.964 & 0 \\
Autocorrelation (lag 4) in monthly return volatility & 0.094 & 0.891 & 0.895 & 0.040 & 0.963 & 0.959 & 0 \\
\hline
\end{tabular}

$D_{0}=1$, we find an astonishingly high average Sharpe-ratio of about 2.65. This also indicates financial instability.

More information on the characteristics of the asset price process is provided in Table 2. This table presents measures of return volatility and of autocorrelation in returns and in return volatility for the benchmark case and for specifications 1 to 3 . The results are given for initial dividends of 1 and 4 . The initial dividend is relevant since it determines the likely dividend paths underlying the simulation results. We compare the asset return characteristics at different initial dividend levels to illustrate the extent of financial instability. In a stable world the characteristics should depend little on the initial dividend.

The volatility of asset returns equals the dividend volatility of 12.8 percent in the benchmark case. It is higher for specifications 1 to 3 because of declining aggregate RRA. For specification 1 and an initial dividend of 1 the return volatility is 16.7 percent on a monthly basis and 16.6 percent on a 4-year basis. These figures are similar for an initial dividend of 4 indicating financial stability. This is completely different for specifications 2 and 3. Not only 


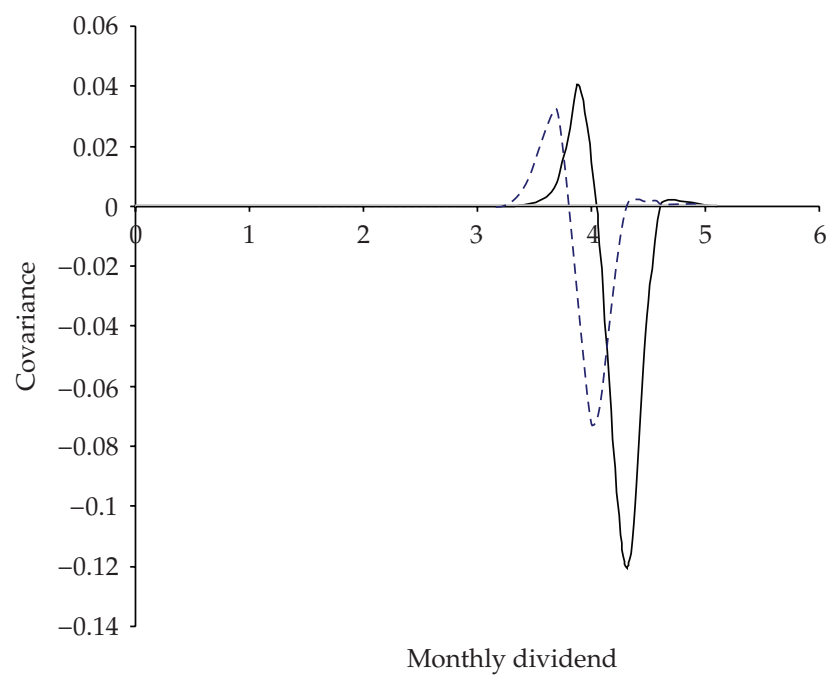

Figure 7: Serial covariance of the asset return as a function of the monthly dividend. The figure shows the serial covariance of the monthly asset return as a function of the monthly dividend for declining aggregate RRA as shown in Specification 1 (gray line), Specification 2 (black line), and Specification 3 (dotted line) (Figures 2-4). In the benchmark case of constant aggregate RRA there is no serial correlation.

are the figures higher, but also they increase dramatically if the initial dividend is 4 , that is, in the center of the crash potential. The strong price movements in this region produce a high volatility. This indicates strong financial instability.

All displayed return autocorrelations are negative, except for the benchmark case. Figure 7 reveals that the serial return covariance is slightly negative everywhere for specification 1, but this is not true for specifications 2 and 3. Here the autocorrelation becomes positive at a dividend level of about 3.5, reaches a peak at about 3.7, respectively, 3.9, and then turns strongly negative before it moves back close to zero. The intuition for this surprising result is as follows. When the dividend moves up from, say, 3.8 to 4.2 , then the asset return is strongly positive as it is when the dividend moves further up in the next period from 4.2 to 4.7 implying positive autocorrelation. But when it moves further up from 4.7 to 5.2 , then the return will be small implying negative autocorrelation. Hence even though Table 2 shows negative autocorrelations, this only indicates that in the specifications of strong financial instability the local negative autocorrelations dominate the local positive ones in our simulations.

Finally, all the autocorrelations in return volatility shown in the last two rows of Table 2 are positive indicating volatility clustering. Again, this does not rule out varying signs of local autocorrelation. The autocorrelations are small for specification 1 but quite high for specifications 2 and 3, in particular, if the initial dividend is 4 . The high volatility in the crash region reinforces volatility clustering. To conclude, the simulations illustrate that instability in the decline of aggregate relative risk aversion induces instability in important characteristics of the asset return process and, thus, financial instability.

\section{Conclusion}

This paper analyzes in a perfect capital market with rational investors the impact of heterogeneous risk preferences on financial stability. First, it is shown that asset pricing 
is likely to be characterized by declining aggregate relative risk aversion (RRA). Financial instability is largely driven by the pattern of aggregate RRA. If it declines smoothly then stock returns display rather stable characteristics. This is not the case if aggregate RRA declines strongly in some dividend range and weakly otherwise. Then stock return characteristics display strong instability leading in the extreme to stock market crashes. Whether aggregate RRA declines smoothly, depends on preferences and endowments of investors. If the economy is populated with many investors whose relative risk aversion levels are distributed uniformly across a given range, then aggregate RRA tends to decline smoothly. If there are basically two groups of investors, one with high and the other one with low RRA, then aggregate RRA tends to decline in an irregular pattern generating financial instability. In summary, equilibrium asset returns may display very unstable properties as reflected in expected returns, volatility, and serial correlation.

The findings of the paper are consistent with many empirical findings on stock returns. The model setup is deliberately chosen to be simple to pinpoint the importance of the aggregate RRA pattern for financial instability. Therefore future research should investigate more complicated models taking into consideration more realistic settings. For example, this model does not deal with heterogeneous expectations of investors. Also, this model only analyzes the return of the market portfolio neglecting single stocks. Instability of single stock return characteristics might be different from that of the market portfolio due to idiosyncratic risks.

\section{Appendix}

\section{A. Proofs}

\section{A.1. Proof of Proposition 2.1}

Investor $i$ derives her optimal portfolio of date $\tau$-claims from

$$
\max E\left[u_{i}\left(x_{i}\right)\right] \quad \text { s.t. } E\left[x_{i} \phi\left(D_{\tau}\right)\right]=w_{0 \tau} .
$$

$w_{0 \tau}$ is the investor's endowment reserved for buying claims on $D_{\tau} . \phi\left(D_{\tau}\right)$ is the stochastic discount factor, that is, $\phi\left(D_{\tau}\right)=\Phi_{0, \tau} \exp \left(-r_{f} \tau\right)$. The FOC for $x_{i}$ is $\left(1 / \lambda_{i}\right.$ denotes the Lagrangemultiplier of the budget constraint)

$$
u_{i}^{\prime}\left(x_{i}\right)=\frac{1}{\lambda_{i}} \phi\left(D_{\tau}\right) ; \quad \forall D_{\tau}
$$

Differentiate the $\log$ of this equation with respect to $\ln D_{\tau}$. This yields

$$
\eta_{i}\left(x_{i}\right) \frac{d \ln x_{i}}{d \ln D_{\tau}}=\eta_{M}\left(D_{\tau}\right) ; \quad \forall D_{\tau}
$$


Since $d \ln x_{i} / d \ln D_{\tau}=\left(d x_{i} / d D_{\tau}\right) / \alpha_{i}\left(D_{\tau}\right)$ and $\sum_{i} d x_{i} / d D_{\tau}=1$, aggregating (A.3) across all investors yields

$$
\frac{1}{\eta_{M}\left(D_{\tau}\right)}=\sum_{i} \frac{\alpha_{i}\left(D_{\tau}\right)}{\eta_{i}\left(x_{i}\right)}
$$

Differentiate (A.4) with respect to $D_{\tau}$. This yields

$$
\frac{\eta_{M}^{\prime}\left(D_{\tau}\right)}{\left[\eta_{M}\left(D_{\tau}\right)\right]^{2}}=\sum_{i} \frac{\eta_{i}^{\prime}\left(x_{i}\right)}{\left[\eta_{i}\left(x_{i}\right)\right]^{2}} \frac{d x_{i}}{d D \tau} \alpha_{i}\left(D_{\tau}\right)-\sum_{i} \frac{1}{\eta_{i}\left(x_{i}\right)} \alpha_{i}^{\prime}\left(D_{\tau}\right)
$$

The first term on the right-hand side of (A.5) can be rewritten using (A.3) as

$$
\sum_{i} \frac{\eta_{i}^{\prime}\left(x_{i}\right)}{\left[\eta_{i}\left(x_{i}\right)\right]^{2}} \frac{d \ln x_{i}}{d \ln D_{\tau}}\left[\alpha_{i}\left(D_{\tau}\right)\right]^{2}=\frac{1}{\eta_{M}\left(D_{\tau}\right)} \sum_{i} \frac{\eta_{i}^{\prime}\left(x_{i}\right)}{\eta_{i}\left(x_{i}\right)}\left[\alpha_{i}\left(D_{\tau}\right) \frac{\eta_{M}\left(D_{\tau}\right)}{\eta_{i}\left(x_{i}\right)}\right]^{2}
$$

The second term on the right-hand side of (A.5) can be rewritten as (since $\sum_{i} \alpha_{i}^{\prime}\left(D_{\tau}\right)=0$ )

$$
\begin{aligned}
\sum_{i} \alpha_{i}^{\prime}\left(D_{\tau}\right)\left(\frac{1}{\eta_{i}\left(x_{i}\right)}-\frac{1}{\eta_{M}\left(D_{\tau}\right)}\right) & =\frac{1}{D_{\tau}} \sum_{i} \frac{\alpha_{i}^{\prime}\left(D_{\tau}\right)}{\alpha_{i}\left(D_{\tau}\right)} D_{\tau}\left[\frac{1}{\eta_{i}\left(x_{i}\right)}-\frac{1}{\eta_{M}\left(D_{\tau}\right)}\right] \alpha_{i}\left(D_{\tau}\right) \\
& =\frac{1}{D_{\tau}} \sum_{i} \frac{d \ln \alpha_{i}}{d \ln D_{\tau}}\left[\frac{1}{\eta_{i}\left(x_{i}\right)}-\frac{1}{\eta_{M}\left(D_{\tau}\right)}\right] \alpha_{i}\left(D_{\tau}\right) \\
& =\frac{\eta_{M}\left(D_{\tau}\right)}{D_{\tau}} \sum_{i}\left[\frac{1}{\eta_{i}\left(x_{i}\right)}-\frac{1}{\eta_{M}\left(D_{\tau}\right)}\right]^{2} \alpha_{i}\left(D_{\tau}\right) .
\end{aligned}
$$

The last equation follows from $d \ln \alpha_{i} / d \ln D_{\tau}=d \ln x_{i} / d \ln D_{\tau}-1$ and (A.3) which implies $d \ln \alpha_{i} / d \ln D_{\tau}=\eta_{M}(D \tau)\left[1 / \eta_{i}\left(x_{i}\right)-1 / \eta_{M}\left(D_{\tau}\right)\right]$.

Multiplying the revised equation (A.5) by $\eta_{M}\left(D_{\tau}\right) D_{\tau}$ proves Proposition 2.1.

\section{A.2. Proof of Proposition 2.2}

Intertemporal no-arbitrage implies for dates $s$ and $t$ with $s>t$

$$
\Phi_{0, t}\left(D_{t}\right)=E\left[\Phi_{0, s}\left(D_{s}\right) \mid D_{t}\right]
$$

Taking logs and differentiating with respect to $\ln D_{t}$ yields

$$
\frac{\partial \ln \Phi_{0, t}}{\partial \ln D_{t}}=E\left[\frac{\partial \ln \Phi_{0, s}}{\partial \ln D_{s}} \frac{\partial \ln D_{s}}{\partial \ln D_{t}} \frac{\Phi_{0, s}}{\Phi_{0, t}} \mid D_{t}\right]
$$


This may be written as

$$
\eta_{t}^{\Phi, D}=E\left[\eta_{s}^{\Phi, D} \frac{\partial \ln D_{s}}{\partial \ln D_{t}} \Phi_{t, s} \mid D_{t}\right]
$$

with $\Phi_{t, s}=\Phi_{0, s} / \Phi_{0, t}$. Differentiating $\eta_{t}^{\Phi, D}$ with respect to $\ln D_{t}$ yields

$$
\begin{aligned}
\frac{\partial \eta_{t}^{\Phi, D}}{\partial \ln D_{t}}= & E\left[\frac{\partial \eta_{s}^{\Phi, D}}{\partial \ln D_{s}} \Phi_{t, s}\left(\frac{\partial \ln D_{s}}{\partial \ln D_{t}}\right)^{2} \mid D_{t}\right]+E\left[\eta_{s}^{\Phi, D} \frac{\partial^{2} \ln D_{s}}{\partial \ln D_{t}{ }^{2}} \Phi_{t, s} \mid D_{t}\right] \\
& +E\left[\eta_{s}^{\Phi, D} \frac{\partial \ln D_{s}}{\partial \ln D_{t}} \frac{\partial \ln \Phi_{t, s}}{\partial \ln D_{t}} \Phi_{t, s} \mid D_{t}\right] .
\end{aligned}
$$

Because of the martingale property $\Phi_{0, t}=E\left[\Phi_{0, s} \mid D_{t}\right]$ and $\Phi_{t, s}=\Phi_{0, s} / \Phi_{0, t}$ the elasticity of the (forward) stochastic discount factor $\Phi_{t, s}$ with respect to the dividend $D_{t}$ is given by

$$
\begin{aligned}
\frac{\partial \ln \Phi_{t, s}}{\partial \ln D_{t}} & =\frac{\partial \ln \Phi_{0, s}}{\partial \ln D_{s}} \frac{\partial \ln D_{s}}{\partial \ln D_{t}}-E\left[\frac{\partial \ln \Phi_{0, s}}{\partial \ln D_{s}} \frac{\partial \ln D_{s}}{\partial \ln D_{t}} \Phi_{t, s} \mid D_{t}\right] \\
& =-\eta_{s}^{\Phi, D} \frac{\partial \ln D_{s}}{\partial \ln D_{t}}+E\left[\eta_{s}^{\Phi, D} \frac{\partial \ln D_{s}}{\partial \ln D_{t}} \Phi_{t, s} \mid D_{t}\right] .
\end{aligned}
$$

Hence, the last term in (A.11) equals -Variance ${ }^{\widetilde{P}}\left[\eta_{s}^{\Phi, D}\left(\partial \ln D_{s} / \partial \ln D_{t}\right) \quad \mid \quad D_{t}\right]$, where Variance $^{\tilde{P}}[\cdot]$ is the variance under the equivalent martingale measure $\widetilde{P}$ defined by $\Phi_{t, s}$.

Regarding the sign of $\partial \eta_{t}^{\Phi, D} / \partial \ln D_{t}$ as given by (A.11), if $\partial \eta_{s}^{\Phi, D} / \partial \ln D_{s} \leq 0$, then the first term is negative. The second term is negative for nonaccelerating aggregate consumption, $\partial^{2} \ln D_{s} / \partial \ln D_{t}^{2} \leq 0$. Since the variance is always positive, the third term is also negative. This proves the proposition.

\section{A.3. Proof of Proposition 2.3}

First, we show that, given investors $i=1, \ldots, n$ with constant RRA $\eta_{1} \geq \eta_{2} \geq \cdots \geq \eta_{n}$ and $\eta_{1}>\eta_{n}$

$$
\left|\frac{\partial \ln \eta_{M}\left(D_{\tau}\right)}{\partial \ln D_{\tau}}\right|=\sum_{i=1}^{n} \alpha_{i}\left(D_{\tau}\right)\left(\frac{\eta_{M}\left(D_{\tau}\right)}{\eta_{i}}-1\right)^{2}
$$

attains its maximum if $\alpha_{i}\left(D_{\tau}\right)=0$ for every investor $i$ with $\eta_{i} \in\left(\eta_{n}, \eta_{1}\right)$. To simplify notation, let $1 / \eta_{i} \equiv z_{i}$. Then rewrite

$$
\begin{aligned}
\left|\frac{\partial \ln \eta_{M}\left(D_{\tau}\right)}{\partial \ln D_{\tau}}\right| & =-1+\sum_{i=1}^{n} \alpha_{i}\left(D_{\tau}\right)\left(\frac{\eta_{M}\left(D_{\tau}\right)}{\eta_{i}}\right)^{2} \\
& =-1+\sum_{i=1}^{n} \frac{\alpha_{i}\left(D_{\tau}\right) z_{i}^{2}}{\left[\sum_{i=1}^{n} \alpha_{i}\left(D_{\tau}\right) z_{i}\right]^{2}} .
\end{aligned}
$$


In equilibrium $\alpha_{i}\left(D_{\tau}\right) \geq 0$; for all $i$. Differentiate the last equation with respect to $\alpha_{i}$, subject to $\sum_{i=1}^{n} \alpha_{i}\left(D_{\tau}\right)=1$ and $\alpha_{i}\left(D_{\tau}\right) \geq 0$; for all $i$. This yields the FOC ( $u$ ELagrange - multiplier):

$$
\frac{z_{i}^{2}}{\left[\sum_{j} \alpha_{j}\left(D_{\tau}\right) z_{j}\right]^{2}}-2 z_{i} \sum_{j} \frac{\alpha_{j}\left(D_{\tau}\right) z_{j}^{2}}{\left[\sum_{j} \alpha_{j}\left(D_{\tau}\right) z_{j}\right]^{3}} \leq u ; \quad \forall i .
$$

Except for the factors $z_{i}^{2}$ and $2 z_{i}$ the FOC is the same for all $i$. Hence it can hold as an equality only for two investors. For all other investors $\alpha_{i}^{\star}\left(D_{\tau}\right)=0$. Then the maximum of $\left|\partial \ln \eta_{n}\left(D_{\tau}\right) / \partial \ln \left(D_{\tau}\right)\right|$ is obtained if $\alpha_{1}^{\star}\left(D_{\tau}\right)$ and $\alpha_{n}^{\star}\left(D_{\tau}\right)$ are positive with $\alpha_{1}^{\star}\left(D_{\tau}\right)+\alpha_{n}^{\star}\left(D_{\tau}\right)=$ 1 , for all $D_{\tau}$.

for

Second, given only two investors $(n=2)$, we show that $\left|d \ln \eta_{M} / d \ln D_{\tau}\right|$ is the highest

$$
\alpha_{1}^{\star}=\frac{z_{2}}{\left(z_{1}+z_{2}\right)}=\frac{1 / \eta_{2}}{1 / \eta_{1}+1 / \eta_{2}}=\frac{\eta_{1}}{\eta_{1}+\eta_{2}} .
$$

For $n=2, \alpha_{2}=1-\alpha_{1}$ so that

$$
\left|\frac{d \ln \eta_{M}}{d \ln D_{\tau}}\right|=\frac{\alpha_{1}\left(z_{1}^{2}-z_{2}^{2}\right)+z_{2}^{2}}{\left(\alpha_{1}\left(z_{1}-z_{2}\right)+z_{2}\right)^{2}}-1 .
$$

Differentiate with respect to $\alpha_{1}$. Setting the derivitive equal to zero yields

$$
\left(\alpha_{1}^{\star}\left(z_{1}-z_{2}\right)+z_{2}\right)^{2}\left(z_{1}^{2}-z_{2}^{2}\right)=2\left[\alpha_{1}^{\star}\left(z_{1}^{2}-z_{2}^{2}\right)+z_{2}^{2}\right]\left(z_{1}-z_{2}\right)\left(\alpha_{1}\left(z_{1}-z_{2}\right)+z_{2}\right),
$$

or

$$
\left(\alpha_{1}^{\star}\left(z_{1}-z_{2}\right)+z_{2}\right)\left(z_{1}+z_{2}\right)=2\left[\alpha_{1}^{\star}\left(z_{1}^{2}-z_{2}^{2}\right)+z_{2}^{2}\right]
$$

or

$$
\alpha_{1}^{\star}\left[\left(z_{1}-z_{2}\right)\left\{\left(z_{1}+z_{2}\right)-2\left(z_{1}+z_{2}\right)\right\}\right]=2 z_{2}^{2}-z_{2}\left(z_{1}+z_{2}\right),
$$

or

$$
\alpha_{1}^{\star}\left(z_{1}-z_{2}\right)\left(z_{1}+z_{2}\right)=z_{1} z_{2}-z_{2}^{2}=z_{2}\left(z_{1}-z_{2}\right)
$$

or

$$
\alpha_{1}^{\star}=\frac{z_{2}}{z_{1}+z_{2}}=\frac{1 / \eta_{2}}{1 / \eta_{1}+1 / \eta_{2}}=\frac{\eta_{1}}{\eta_{1}+\eta_{2}} .
$$

This share is the equilibrium share for $D_{\tau}^{\star}$. 
Third, inserting $\alpha_{1}^{\star}$ yields, since $\alpha_{1}^{\star} z_{1}=\alpha_{2}^{\star} z_{2}$,

$$
\left|\frac{d \ln ^{*} \eta_{M}}{d \ln D_{\tau}}\right|=-1+\frac{\left(z_{1}+z_{2}\right)^{2}}{4 z_{1} z_{2}}=1-\frac{\left(\eta_{1} / \eta_{2}+1\right)^{2}}{4\left(\eta_{1} / \eta_{2}\right)} .
$$

In addition, $\eta_{M}\left(D_{\tau}^{\star}\right)=\left(\eta_{1}+\eta_{2}\right) / 2$ follows.

\section{A.4. Proof of Proposition 3.1}

Differentiating the logarithm of equation with respect to $\ln D_{t}$ and using $\partial \ln D_{s} / \partial \ln D_{t}=1$ and (A.12) yields after some manipulation

$$
\begin{aligned}
\eta_{t}^{S, D} & =1+\frac{\int_{t}^{\infty} \exp \left(-r_{f}(s-t)\right) E\left(D_{s} \Phi_{t, s}\left(-\eta_{s}^{\Phi, D}+E\left(\eta_{s}^{\Phi, D} \Phi_{t, s} \mid D_{t}\right)\right) \mid D_{t}\right) d s}{S_{t}} \\
& =1-\frac{1}{S_{t}} \int_{t}^{\infty} \frac{\operatorname{cov}^{\tilde{P}}\left(D_{s}, \eta_{s}^{\Phi, D} \mid D_{t}\right)}{\exp \left(r_{f}(s-t)\right)} d s
\end{aligned}
$$

where $\operatorname{cov}^{\tilde{P}}(\cdot)$ is the covariance under the martingale measure $\widetilde{P}$. Thus, if $\eta_{s}^{\Phi, D}$ is constant, then $\eta_{t}^{S, D} \equiv \partial \ln S_{t} / \partial \ln D_{t}=1$. Declining aggregate RRA, $\partial \eta_{s}^{\Phi, D} / \partial D_{s}<0$, implies $\operatorname{cov}^{\tilde{P}}\left(D_{s}, \eta_{s}^{\Phi, D} \mid D_{t}\right)<0$ and, hence, $\eta_{t}^{S, D}>1$. Increasing aggregate RRA, $\partial \eta_{s}^{\Phi, D} / \partial D_{s}>0$, implies $\eta_{t}^{S, D}<1$. The last sentence in Proposition 3.1 follows directly from (3.5).

\section{A.5. Proof of Proposition 3.2}

We know that for constant aggregate RRA

$$
\operatorname{Var}\left(\ln \frac{V_{\tau}}{V_{t}} \mid D_{t}\right)=\operatorname{Var}\left(\ln \frac{D_{\tau}}{D_{t}} \mid D_{t}\right), \quad t<\tau
$$

By Proposition 2.1, for declining aggregate RRA $\eta_{t}^{\Phi, D}$, the elasticity is $\eta_{t}^{S, D}>1$ so that the conditional variance of asset returns is higher than the (conditional) variance of the dividend process, that is,

$$
\operatorname{Var}\left(\ln \frac{V_{\tau}}{V_{t}} \mid D_{t}\right)>\operatorname{Var}\left(\ln \frac{D_{\tau}}{D_{t}} \mid D_{t}\right), \quad t<\tau
$$

Consider now the unconditional variance (i.e., $\theta=0$ ):

$$
\operatorname{Var}\left(\ln \frac{V_{\tau}}{V_{t}}\right)=\operatorname{Var}\left(E\left(\ln V_{\tau} \mid D_{t}\right)-\ln V_{t}\right)+E\left(\operatorname{Var}\left(\ln V_{\tau} \mid D_{t}\right)\right)
$$


with

$$
E\left(\ln V_{\tau} \mid D_{t}\right)-\ln V_{t}=E\left(\int_{t}^{\tau}\left(\mu_{V}\left(S_{s}\right)-\frac{1}{2} \Sigma_{V}\left(S_{s}\right)^{2}\right) d s \mid D_{t}\right)
$$

We need to show that $\operatorname{Var}\left(\ln \left(V_{\tau} / V_{t}\right)\right)$ is greater than

$$
\operatorname{Var}\left(\ln \frac{D_{\tau}}{D_{t}}\right)=\operatorname{Var}\left(\ln D_{\tau} \mid D_{t}\right)
$$

From (A.26) it follows that the second term on the right-hand side of (A.27) exceeds $\operatorname{Var}\left(\ln \left(D_{\tau} / D_{t}\right)\right)$. As the first term on the right-hand side of (A.27) is also positive, we are done. The proof is the same for the variance conditional on $D_{\theta} ; 0<\theta<t$. The conditional total return variance increases if $\eta^{S, D}$ increases everywhere. Hence, variability of overreaction implies variability in the conditional total return variance.

\section{A.6. Proof of Proposition 3.3}

Since by definition $\mathrm{CER}_{t, \tau} \equiv \int_{t}^{\tau}\left(d S_{s} / S_{s}\right)+\int_{t}^{\tau}\left(D_{s} / S_{s}-r_{f}\right) d s$, and the riskless rate $r_{f}$ is assumed constant, the covariance is given by

$$
\begin{aligned}
\operatorname{Cov}\left(\mathrm{CER}_{t, \tau}, \mu_{V}\left(S_{\tau}\right)-r_{f} \mid D_{t}\right)= & \operatorname{Cov}\left(\int_{t}^{\tau} \frac{d S_{s}}{S_{s}}+\int_{t}^{\tau} \frac{D_{s}}{S_{s}} d s, \int_{t}^{\tau} d \mu_{V}\left(S_{s}\right) \mid D_{t}\right) \\
=E( & {\left[\int_{t}^{\tau} \frac{d S_{s}}{S_{s}}+\int_{t}^{\tau} \frac{D_{s}}{S_{s}} d s-E\left(\int_{t}^{\tau} \frac{d S_{s}}{S_{s}}+\int_{t}^{\tau} \frac{D_{s}}{S_{s}} d s \mid D_{t}\right)\right] } \\
\times & {\left.\left[\int_{t}^{\tau} d \mu_{V}\left(S_{s}\right)-E\left(\int_{t}^{\tau} d \mu_{V}\left(S_{s}\right) \mid D_{t}\right)\right] \mid D_{t}\right) . }
\end{aligned}
$$

By (3.4), $\mu_{V}\left(S_{t}\right)=\eta_{t}^{\Phi, D} \eta_{t}^{S, D} \sigma_{D}^{2}+r_{f}$ and $\Sigma_{S}\left(S_{t}\right)=\eta_{t}^{\mathrm{S}, D} \sigma_{D}$. Since $V_{t}=\alpha_{t} S_{t}$, we obtain $\eta_{t}^{S, D}=\eta_{t}^{V, D}$ and $\Sigma_{V}\left(S_{t}\right)=\Sigma_{S}\left(S_{t}\right)=\eta_{t}^{V, D} \sigma_{D}$. Hence we can rewrite the covariance as

$$
\begin{gathered}
E\left(\left(\int_{t}^{\tau} \eta_{s}^{V, D} \sigma_{D} d W_{s}\right)\left(\int_{t}^{\tau}\left\{\eta_{s}^{V, D} \frac{\partial \eta_{s}^{\Phi, D}}{\partial D_{s}}+\eta_{s}^{\Phi, D} \frac{\partial \eta_{s}^{V, D}}{\partial D_{s}}\right\} \sigma_{D}^{3} D_{s} d W_{s}\right) \mid D_{t}\right) \\
=\int_{t}^{\tau} E\left(\left\{\eta_{s}^{V, D} \frac{\partial \eta_{s}^{\Phi, D}}{\partial D_{s}}+\eta_{s}^{\Phi, D} \frac{\partial \eta_{s}^{V, D}}{\partial D_{s}}\right\} \sigma_{D}^{4} D_{s} \eta_{s}^{V, D} \mid D_{t}\right) d s
\end{gathered}
$$

since by Ito's Lemma the stochastic part of $d \mu_{V}\left(S_{t}\right)$ is given by

$$
\frac{\partial\left(\eta_{t}^{\Phi, D} \eta_{t}^{V, D} \sigma_{D}^{2}+r_{f}\right)}{\partial D_{t}} \sigma_{D} D_{t} d W_{t}
$$


The elasticities $\eta_{s}^{V, D}$ and $\eta_{s}^{\Phi, D}$ are positive. Hence, $\operatorname{Cov}\left(\mathrm{CER}_{t, \tau}, \mu_{V}(V \tau)-r_{f} \mid D_{t}\right)<[>] 0$ if aggregate RRA is declining (increasing) and $\eta_{s}^{V, D}$ is nonincreasing (nondeclining) in $D_{s}$. The latter condition is equivalent to the condition that the instantaneous volatility of the return index, $\Sigma_{V}\left(S_{s}\right)$, is not increasing (not declining) because $\Sigma_{V}\left(S_{s}\right)=\eta_{s}^{V, D} \sigma_{D}$.

\section{A.7. The Price of the Market Portfolio}

The price of the market portfolio at date $t, S_{t}$, is

$$
\begin{aligned}
S_{t}= & \sum_{s=t}^{t+h} \exp \left(r_{f}(t-s)\right) E\left[D_{s} \Phi_{t, s} \mid D_{t}\right)+\exp \left(-r_{f} h\right) E\left(d p D_{t+h}^{\vartheta} \Phi_{t, t+h} \mid D_{t}\right) \\
= & A \sum_{s=t}^{t+h} \exp \left(r_{f}(t-s)\right) \sum_{i=1}^{N} D_{t}^{1-\delta_{i} \vartheta} B_{t, s}^{i} \exp \left[\left(1-\delta_{i} \vartheta(s-t)\right)\left\{\frac{\mu_{D}-\delta_{i} \vartheta \sigma_{D}^{2}}{2}\right\}\right] \\
& +A \exp \left(-r_{f} h\right) \sum_{i=1}^{N} D_{t}^{\vartheta\left(1-\delta_{i}\right)} \beta_{i} d p^{1-\delta_{i}} \exp \left[\left(1-\delta_{i}\right) \vartheta h\left\{\frac{\mu_{D}-\left[\left(1-\delta_{i}\right) \vartheta-1\right] \sigma_{D}^{2}}{2}\right\}\right]
\end{aligned}
$$

with

$$
\begin{gathered}
A^{-1} \equiv \sum_{i=1}^{N} D_{t}^{-\delta_{i} \vartheta} B_{t, t}^{i} \\
B_{t, s}^{i} \equiv \beta_{i} d p^{-\delta_{i}} \exp \left[-\delta_{i} \vartheta(t+h-s)\left\{\frac{\mu_{D}-\left[\delta_{i} \vartheta+1\right] \sigma_{D}^{2}}{2}\right\}\right] .
\end{gathered}
$$

\section{Acknowledgments}

The authors are grateful to Axel Adam-Müller, Yacine Ait-Sahalia, Yakov Amihud, Andrew Ang, Volker Böhm, Menachem Brenner, Wolfgang Bühler, Antonio Camara, Peter Carr, Damien Chabi-Yo, David Feldman, Stephen Figlewski, Jens Jackwerth, Tao Lin, Harris Schlesinger, Sophie Shive, Siegfried Trautmann, Hongjun Yan, and Robert Whitelaw for helpful discussions. Comments from seminar participants at the GEABA Meeting in Berlin, the Symposium on Finance, Banking and Insurance in Karlsruhe, the MFA Meeting in St. Louis, the EFA Meeting in Lake Buena Vista, the Meeting of the Verein für Socialpolitik in Zurich, the FMA Meeting in Denver, the NFA Meeting in Quebec, the EFMA Meeting in Basle, the ESEM in Madrid, the EFA Meeting in Moscow and at Concordia University, the University of Konstanz, Laval University, McMaster University, New York University, and Syracuse University have been helpful to them. Financial support by the Institut de Finance Mathématique de Montréal, the CoFE (University of Konstanz), the ZEW (Mannheim), and a grant by the Deutsche Bundesbank is gratefully acknowledged. 


\section{References}

[1] R. J. Shiller, Irrational Exuberance, Princeton University Press, Princeton, NJ, USA, 2000.

[2] J. Wang, "The term structure of interest rates in a pure exchange economy with heterogeneous investors," Journal of Financial Economics, vol. 41, pp. 75-110, 1996.

[3] J. Y. Campbell and J. H. Cochrane, "By force of habit: a consumption-based explanation of aggregate stock market behavior," Journal of Political Economy, vol. 107, no. 2, pp. 205-251, 1999.

[4] Y. L. Chan and L. Kogan, "Catching up with the Joneses: heterogeneous preferences and the dynamics of asset prices," Journal of Political Economy, vol. 110, no. 6, pp. 1255-1285, 2002.

[5] Y. Aït-Sahalia and A. W. Lo, "Nonparametric risk management and implied risk aversion," Journal of Econometrics, vol. 94, no. 1-2, pp. 9-51, 2000.

[6] J. C. Jackwerth, "Recovering risk aversion from option prices and realized returns," Review of Financial Studies, vol. 13, pp. 433-451, 2000.

[7] J. V. Rosenberg and R. F. Engle, "Empirical pricing kernels," Journal of Financial Economics, vol. 64, pp. 341-372, 2002.

[8] R. Bliss and N. Panigirtzoglou, “Option-implied risk aversion estimates,” Journal of Finance, vol. 59, pp. 407-446, 2004.

[9] R. F. Dittmar, "Nonlinear pricing kernels, kurtosis preference, and evidence from the cross section of equity returns," Journal of Finance, vol. 57, no. 1, pp. 369-403, 2002.

[10] G. Barone-Adesi, R. F. Engle, and L. Mancini, "A GARCH option pricing model with filtered historical simulation," Review of Financial Studies, vol. 21, no. 3, pp. 1223-1258, 2008.

[11] S. Benninga and J. Mayshar, "Heterogeneity and option pricing," Review of Derivatives Research, vol. 4, pp. 7-27, 2000.

[12] A. Bick, "On the consistency of the Black-Scholes model with a general equilibrium framework," Journal of Financial and Quantitative Analysis, vol. 22, no. 3, pp. 259-275, 1987.

[13] G. Franke, R. C. Stapleton, and M. G. Subrahmanyam, "When are options overpriced? The BlackScholes model and alternative characterisations of the pricing kernel," European Finance Review, vol. 3, pp. 79-102, 1999.

[14] F. Black and M. Scholes, "The pricing of options and corporate liabilities," Journal of Political Economy, vol. 81, pp. 637-654, 1973.

[15] R. C. Stapleton and M. G. Subrahmanyam, "Risk aversion and the intertemporal behavior of asset prices," Review of Financial Studies, vol. 3, pp. 677-693, 1990.

[16] F. Gomes and A. Michaelidis, "Asset pricing with limited risk sharing and heterogeneous agents," Review of Financial Studies, vol. 21, pp. 415-448, 2008.

[17] M. J. Brennan, A. W. Wang, and Y. Xia, "Estimation and test of a simple model of intertemporal capital asset pricing," Journal of Finance, vol. 59, no. 4, pp. 1743-1775, 2004.

[18] M. J. Brennan and Y. Xia, "Risk and valuation under an intertemporal capital asset pricing model," Journal of Business, vol. 79, no. 1, pp. 1-35, 2006.

[19] D. M. Kreps and E. L. Porteus, "Temporal resolution of uncertainty and dynamic choice theory," Econometrica, vol. 46, no. 1, pp. 185-200, 1978.

[20] L. G. Epstein and S. E. Zin, "Substitution, risk aversion, and the temporal behavior of consumption and asset returns: a behavorial framework," Econometrica, vol. 57, no. 4, pp. 937-969, 1989.

[21] B. Düring and E. Lüders, "Option prices under generalized pricing kernels," Review of Derivatives Research, vol. 8, no. 2, pp. 97-123, 2005.

[22] E. Ghysels, A. C. Harvey, and E. Renault, "Stochastic volatility," in Statistical Methods in Finance, vol. 14 of Handbook of Statistics, pp. 119-191, North-Holland, Amsterdam, The Netherlands, 1996.

[23] A. Ang and G. Bekaert, "Stock return predictability: is it there?" Review of Financial Studies, vol. 20, pp. 651-707, 2007.

[24] T. C. Johnson, "Rational momentum effects," Journal of Finance, vol. 57, pp. 585-608, 2002.

[25] M. Brunnermeier, Asset Pricing Under Asymmetric Information, Oxford University Press, Oxford, UK, 2001. 


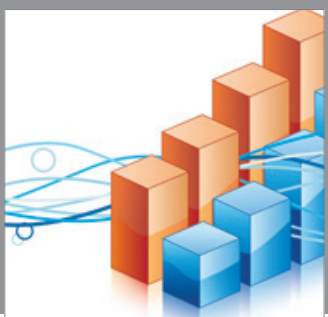

Advances in

Operations Research

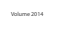

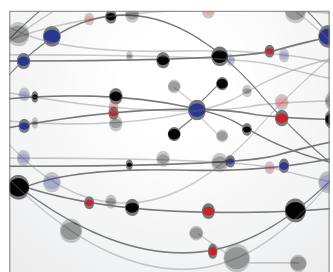

\section{The Scientific} World Journal
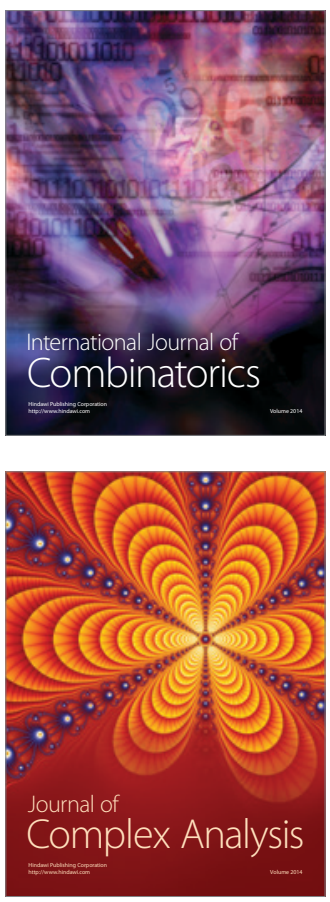

International Journal of

Mathematics and

Mathematical

Sciences
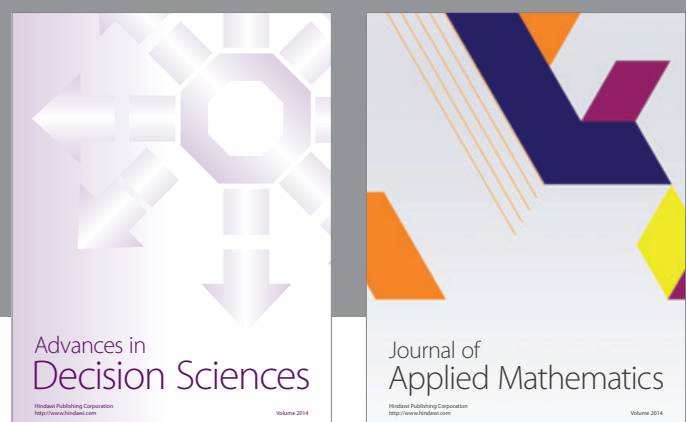

Journal of

Applied Mathematics
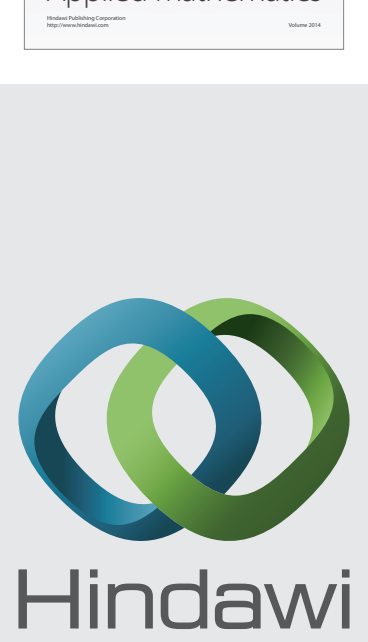

Submit your manuscripts at http://www.hindawi.com
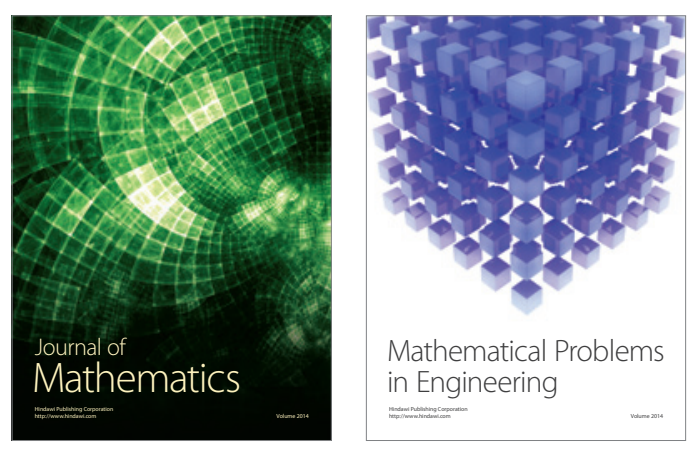

Mathematical Problems in Engineering
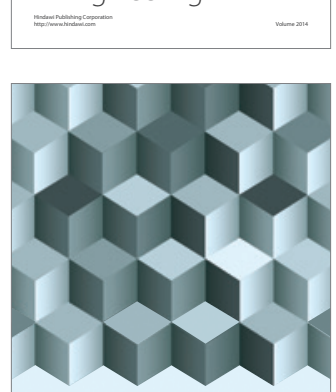

Journal of

Function Spaces
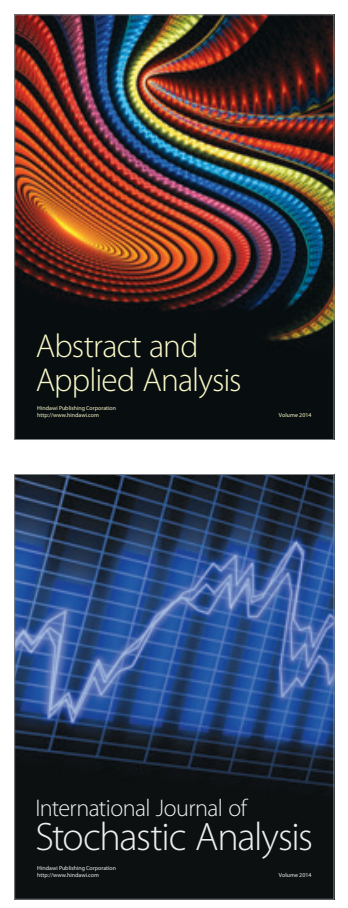

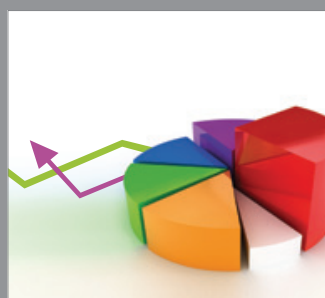

ournal of

Probability and Statistics

Promensencen
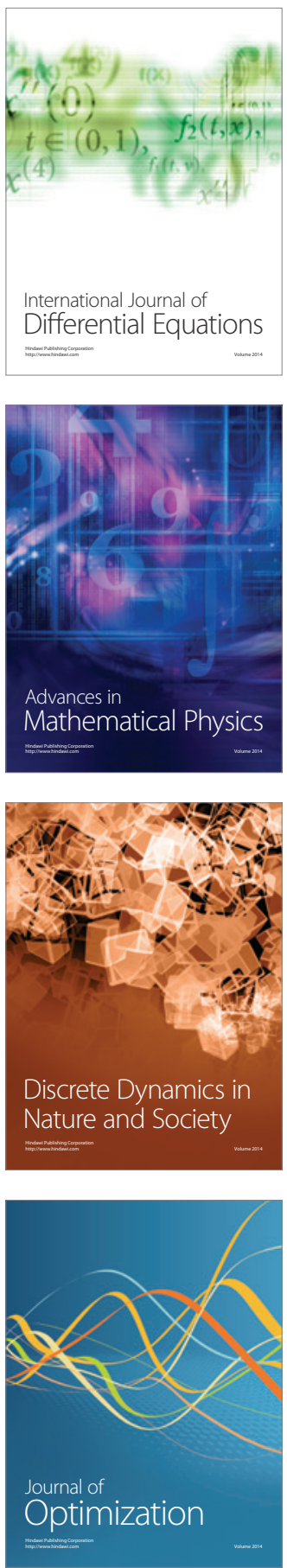